Martha del Socorro Alzate Cárdenas*

Olga Lucía Arboleda Álvarez"

Oswaldo Antonio Salgado Cañaveral

Fundación Universitaria Luis Amigó, Medellín, Colombia

Recibido: 25 de enero de 2016

Concepto de evaluación: 11 de mayo de 2016

Aprobado: 27 de mayo de 2016

Artículo de investigación (C) 2016 Universidad Católica de Colombia. Facultad de Ciencias Económicas y Administrativas. Todos los derechos reservados

* Economista. Especialista en Alta Gerencia. Magíster en Educación. Docente, Facultad de Ciencias Administrativas Económicas y Contables, Programa de Administración de Empresas, Fundación Universitaria Luis Amigó, Medellín, Colombia. Dirección de correspondencia: Transversal $51 \mathrm{~A} \mathrm{~N}^{\circ} 67 \mathrm{~B}-90$, of. 1-209,

Medellín, Colombia. Correo electrónico: martha.alzateca@amigo.edu.co

** Historiadora. Especialista en Docencia Investigativa Universitaria. Magíster en Salud Pública. Docente, Facultad de Ciencias Administrativas

Económicas y Contables, Programa de Administración de Empresas, Fundación Universitaria Luis Amigó, Medellín, Colombia. Dirección de correspondencia: Transversal 51A N $\mathrm{N}^{\circ}$ 67B-90, of. 1-412, Medellín, Colombia. Correo electrónico: oarboled@funlam.edu.co
Finanz. polit. econ., ISSN: 2248-6046, Vol. 8, No. 2, julio-diciembre, 2016, pp. 401-430

http://dx.doi.org/10.14718/revfinanzpolitecon.2016.8.2.9

\section{Retos de la Alcaldía de Medellín para la aplicación de la Política Pública de Economía Social y Solidaria*}

\section{RESUMEN}

La Administración Municipal tiene grandes retos para la superación de problemáticas sociales y la generación de desarrollo equitativo e incluyente. Para ello busca aplicar la Política Pública de Economía Social y Solidaria, al igual que crear, fortalecer y consolidar Unidades Productivas Asociativas (UPA). La metodología utilizada se apoya en el enfoque de investigación cualitativa-interpretativa y usa como técnica entrevistas semiestructuradas a representantes legales de organizaciones sociales y solidarias intervenidas por la Alcaldía de Medellín. Los resultados muestran que no es suficiente proporcionar condiciones necesarias para el surgimiento de estas iniciativas, sino lograr su fortalecimiento y consolidación en el mercado.

Palabras clave: políticas públicas, economía solidaria, organizaciones sociales, emprendimiento.

JEL: L31, L26, I31, M13

\section{Challenges faced by Medellín City Council in the application of public policy for Social and Solidarity-Based Economy}

\section{ABSTRACT}

The Municipal Administration faces great challenges in overcoming social problems and the generation of equal and inclusive development. In view of this, it seeks to apply the public policy for a social and solidarity-based economy, and to create, strengthen, and consolidate Associative Production Units (APU). The methodology used is supported by a qualitative and

\footnotetext{
Este artículo surge del proyecto de investigación "Evaluación de efectividad: Política Pública de Economía Solidaria 2008-2015, según indicadores de Planes de Desarrollo 2008-2011 (Medellín es solidaria y competitiva) y 2012-2015 (Medellín, un hogar para la vida)", desarrollado en convenio entre la Personería de Medellín y el grupo de investigación en Economía Solidaria (Ecosol) de la Fundación Universitaria Luis Amigó.
} 
*** Economista. Especialista en Finanzas. Docente, Facultad de Ciencias Administrativas, Económicas y Contables, Programa de Administración de Empresas, Fundación Universitaria Luis Amigó, Medellín, Colombia. Dirección de correspondencia: Transversal $51 \mathrm{~A} \mathrm{~N} \mathrm{~N}^{\circ} 67 \mathrm{~B}-90$, of. 1-412, Medellín, Colombia. Correo electrónico: oswaldo.salgadoca@amigo.edu.co interpretive research method and uses semi-structured interviews with the legal representatives of social and solidarity-based organizations intervened by Medellín City Council. The results show that it is not enough to provide the necessary conditions for the emergence of such initiatives, but rather they have to be strengthened and consolidated in the market.

Keywords: public policies, solidarity-based economy, social organizations, entrepreneurship.

\section{Desafios da Prefeitura de Medellín para a aplicação da política pública de economia social e solidária}

\section{RESUMO}

A Administração Municipal tem grandes desafios para a superação de problemáticas sociais e para a geração de desenvolvimento equitativo e inclusivo. Para isso, busca aplicar a política pública de economia social e solidária, assim como criar, fortalecer e consolidar Unidades Produtivas Associativas (UPA). A metodologia utilizada se apoia na pesquisa qualitativa-interpretativa e usa como técnicas entrevistas semiestruturadas a representantes legais de organizações sociais e solidárias intermediadas pela Prefeitura de Medellín (Colômbia). Os resultados mostram que não é suficiente proporcionar condições necessárias para o surgimento dessas iniciativas, é necessário também conseguir seu fortalecimento e consolidação no mercado.

Palavras-chave: políticas públicas, economia solidária, organizações sociais, empreendimento 


\section{INTRODUCCIÓN}

Medellín se ha sometido a un proceso de transformación que le permite destacarse, en los ámbitos nacional e internacional, como una ciudad con gran proyección y un enorme potencial de desarrollo económico, social, educativo y cultural (Alcaldía de Medellín, 2014a). Tal proceso ha requerido esfuerzos encaminados a cambiar la percepción de la ciudad con acciones que permiten generar condiciones propicias para mejorar su imagen, atraer inversión y consolidarla como centro de negocios.

Los resultados al respecto no se han hecho esperar: avances e innovaciones, transformaciones de infraestructura y movilidad, entre otros, han llamado la atención del mundo y le han merecido importantes logros y reconocimientos; ejemplo de ello fue la elección como la ciudad más innovadora en 2013, distinción otorgada por la Fundación Rockefeller por ser una de las cien ciudades resilientes del mundo, y por el hecho de acoger, cada vez con más frecuencia, eventos de talla mundial que persiguen el fomento del desarrollo inclusivo y la transformación social (Álvarez y Loaiza, 2015), entre los que se destacan el Foro Urbano Mundial de Naciones Unidas, en 2013, la Asamblea General de la Organización Mundial del Turismo (OMT), en 2015, y la VII Conferencia Latinoamericana y Caribeña de Ciencias Sociales: "Transformaciones democráticas, justicia social y procesos de paz", en 2015.

No obstante, y según lo establecen los dos últimos planes de desarrollo de Medellín ${ }^{1}$, junto a esas importantes transformaciones coexisten realidades de convivencia, seguridad y condiciones de vida de la población que reflejan problemáticas estructurales sin solución de fondo desde las medidas adoptadas. Una de esas situaciones, que en la actualidad representa un verdadero reto, está relacionada con la necesidad de generar desarrollo económico con equidad, incluyente, que procure y garantice oportunidades de acceso y mejoramiento

1 Planes de desarrollo 2008-2011 ("Medellín es solidaria y competitiva") y 2012-2015 ("Medellín, un hogar para la vida"). significativo de las condiciones de vida para sectores sociales más desfavorecidos y en condición de vulnerabilidad.

Al respecto, cabe anotar que si bien las decisiones en materia económica han arrojado resultados positivos, que permiten afianzar la posición estratégica de la ciudad para la generación de desarrollo, aún subyacen situaciones problema que traen consigo consecuencias visiblemente desfavorables (Alcaldía de Medellín, 2014b).

Precisamente, al hacer lectura de la información suministrada por el Departamento Administrativo Nacional de Estadística (DANE, 2015a), se generan reflexiones acerca de la creación de empleos, pues aunque la ciudad ha logrado vincularse a la dinámica nacional de empleo, ahora la discusión se ha trasladado al campo cualitativo, por cuanto se evidencia una desmejora en calidad que se hace visible en problemáticas como informalidad y subempleo.

En relación con la informalidad, vale la pena mencionar que si bien en los últimos años se ha logrado reducir la proporción de personas con trabajos informales, que para 2003 se situaba por encima del $60 \%$ (Alcaldía de Medellín, 2004), las cifras entregadas por el DANE (2015a) señalan que para el 2014 la cifra de empleo informal es de $47,47 \%$, porcentaje muy alto si se tiene en cuenta la inestabilidad y vulnerabilidad a la que están expuestas estas personas.

Con respecto al subempleo, las mediciones del mercado laboral en la ciudad presentan una tasa de subempleo subjetivo del $29,2 \%$ en el último trimestre del 2015 y de subempleo objetivo del 11\% (DANE, 2015b). De ahí que sea importante indicar que al mirar la tendencia de las cifras en los últimos años, el subempleo en la ciudad haya crecido ${ }^{2}$, situación que no solo refleja la insatisfacción de buena parte de la población ocupada respecto a las condiciones laborales, sino que además

2 La información del DANE sobre la situación del mercado laboral en Medellín y su Área Metropolitana muestra un incremento de la tasa de subempleo subjetivo en los últimos años, que pasó de niveles por debajo del $20 \%$ a finales del 2005 a un $29,2 \%$ en el trimestre móvil comprendido entre octubre y diciembre de 2015 . 
demanda mayor atención por parte del Estado y de los actores privados sobre este tema, con el fin de potenciar la sostenibilidad del empleo en la ciudad y aportar al mejoramiento de la calidad de vida de las personas.

Ante este panorama, las últimas administraciones municipales han emprendido acciones para hacer frente a desigualdades existentes en términos de acceso a oportunidades y posibilidades de desarrollo. De este modo, desde el cuatrienio comprendido entre el 2004 y el 2007 se gestaron iniciativas encaminadas a consolidar una cultura de emprendimiento social y solidario en la ciudad.

Así, el Plan de Desarrollo 2004-2007: "Medellín, compromiso de toda la ciudadanía" (Alcaldía de Medellín, 2004) no solo abordó la problemática existente respecto al empleo, el autoempleo, la generación de ingresos y el mejoramiento de condiciones de vida de la población, sino que además planteó la necesidad de promover los movimientos de economía solidaria, para dejar de lado la visión de que la solidaridad debe aparecer después de que la economía ha cumplido la tarea y completado el ciclo; esto implicaba otorgarle al Estado un papel de tratamiento asistencialista frente a la problemática del desempleo, para propiciar un mayor nivel de productividad en empresas de tipo asociativo que les permita ser sostenibles $y$ competitivas en el mercado.

Resulta significativo analizar la puesta en marcha de estas iniciativas y el hecho de que las siguientes administraciones dieran continuidad, mediante programas y proyectos contemplados en los respectivos planes de gobierno, a ese propósito de lograr consolidación de una cultura de emprendimiento social y solidario (Alcaldía de Medellín, 2008a; Alcaldía de Medellín, 2012). Esto ha hecho que tal propósito se convierta en una verdadera apuesta de ciudad, sobre la cual se tienen grandes expectativas para la generación de desarrollo económico equitativo e incluyente.

Ante la situación descrita, este artículo plantea los retos enfrentados por la Alcaldía de Medellín con la aplicación de la Política Pública de Economía Social y Solidaria, y con la creación, el fortalecimiento y la consolidación de Unidades Productivas Asociativas (UPA) en la ciudad, teniendo en cuenta los indicadores planteados en los dos últimos planes de desarrollo.

El artículo contiene cuatro secciones: la primera aborda consideraciones teóricas relacionados con política pública, economía solidaria, emprendimiento solidario, desarrollo humano y empleo; la segunda describe la metodología utilizada en la ejecución de la investigación; la tercera presenta la discusión en función de los resultados, y finalmente se muestran las conclusiones generales en clave de retos enfrentados por la Alcaldía de Medellín al aplicar la Política Pública de Economía Social y Solidaria.

\section{CONSIDERACIONES TEÓRICAS}

\section{Política pública aplicada a Unidades Productivas Asociativas}

Hoy en día es cada vez más común escuchar personas, en diversos escenarios, que hacen alusión a la necesidad de formular y poner en ejecución políticas públicas de diferente índole, para hacer frente a situaciones que representan retos o que se han convertido en una problemática para la sociedad y, por ende, precisan de una intervención estatal que permita subsanarla. Tal situación lleva a cuestionarse sobre el motivo por el cual este concepto se torna tan recurrente al momento de diagnosticar y plantear soluciones a las realidades que afectan las sociedades contemporáneas; también hace necesario profundizar en el significado y relevancia para el desarrollo de estas.

El concepto política pública contiene la palabra política, que el Diccionario de la lengua española (RAE, 2014) define así: "Del lat. politǐcus,

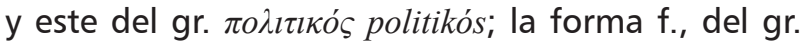

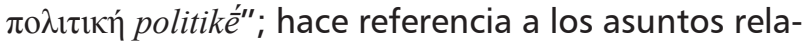
tivos a la doctrina y actividades políticas; mientras que la palabra público viene del latín publǐcus, es decir, "perteneciente o relativo a todo el pueblo". 
A la luz de lo anterior, podría pensarse que se trata de dos términos que distan entre sí, cuando en realidad guardan una estrecha relación, como lo plantea Guerrero (2000):

Ambas palabras proceden de la raíz pul (multiplicidad, amplitud); de esta misma derivó en el griego la palabra polis (Ciudad, Estado), origen del concepto de política, y en el latín populus (pueblo), que es un sustantivo producido por la reduplicación de la voz pul. El sustantivo populus se adjetivó en puplicus y luego en publicus, de donde derivó la palabra público. Así política y público, además de este parentesco etimológico tienen un significado conceptual común: ambas se refieren a lo colectivo, lo comunitario (citado en Salgado, Alzate, Peralta y Pareja, 2015, p. 55).

De igual manera, Deubel y Noel (2002) indican que estos términos representan por sí solos varios significados:

La política (polity), concebida como el ámbito del gobierno de las sociedades humanas; la política (politics), como la actividad de organización y lucha por el control del poder. Y por último, la política (policy), como designación de los propósitos y programas de las autoridades públicas (citados en Salgado et al., 2015, p. 56).

Para este artículo se tomó el significado relacionado con la política pública en términos de propósitos y programas. Conviene advertir que a lo largo de la historia se han generado políticas públicas cambiantes, representadas en la realización concreta de programas y proyectos que avalan las decisiones del Estado en la intervención de las necesidades sociales, es decir, un enfoque teórico mixto de políticas públicas que involucran sociedad y Estado. Para este caso, la sociedad se visibiliza mediante diferentes expresiones de la economía solidaria.
También es importante destacar que las políticas públicas implementadas por el Estado involucran de manera directa al ciudadano y, por tanto, son decisiones que lo afectan; de ahí que se utilice el término público y se haga visible una relación Estado-ciudadano para intervenir problemáticas sociales que impactan una comunidad. Tal relación la percibe Muller (2010) cuando manifiesta: "No se puede separar el juego político de la acción pública, ya que se apoyan mutuamente y por tanto sus combinaciones permiten interpretar las transformaciones de la sociedades contemporáneas" (p. 31).

En el medio local, ese sentido colectivo, derivado desde la propia definición conceptual, se hace explícito en lo expuesto por Gómez et al. (2012), al referirse a las políticas públicas en función de las soluciones específicas de cómo manejar los asuntos públicos o las situaciones sociales problemáticas, las cuales son definidas a partir de las necesidades de una población y teniendo presente una conciencia colectiva de necesidades, propósitos y objetivos comunes que puedan lograrse.

Los autores también sugieren la unión de consensos, ya que la función es promover, proteger y comparar todos los aspectos enfocados a la participación de cada uno de los ciudadanos; orientan además los procesos de participación ciudadana para definir la destinación de recursos estatales en forma eficiente, de manera tal que impacten y solucionen el mayor número de necesidades básicas insatisfechas con miras al desarrollo social. Ello sugiere una movilización de todos los actores sociales en función de lo que se puede y desea lograr.

Asimismo, es importante comprender una política pública en el ámbito de la legitimidad de las herramientas de planificación de un territorio, que también son avaladas por las comunidades; herramientas que configuran el modelo de desarrollo integral para una región o una localidad. En ese sentido, cabe anotar que para la investigación se tuvo como referencia la Política Pública de Economía Social y Solidaria aplicada en los planes de desarrollo de 2008-2011 y 2012-2015, en especial en aquellos programas y proyectos dirigidos a 
promover y apoyar la creación, el fortalecimiento y la consolidación de UPA.

El Plan de Desarrollo 2008-2011: “Medellín es solidaria y competitiva" trata esta temática en el primer componente de la línea tres, "Desarrollo económico e innovación", proyecto "Economía solidaria", definido en los siguientes términos:

Fortalecimiento a la cultura del emprendimiento solidario mediante el desarrollo de iniciativas vinculadas al fomento de buenas prácticas de la economía asociativa y solidaria; la vinculación de iniciativas de economía solidaria al desarrollo local, la educación alrededor de la economía solidaria; el fortalecimiento de unidades de economía solidaria, el desarrollo e implementación de nuevas formas asociativas como: el trueque, los circuitos barriales, los circuitos económicos solidarios, los emprendimientos sociales $y$ el fortalecimiento de organizaciones de segundo grado (Alcaldía de Medellín, 2008a, p. 159).

Por su parte, el Plan de Desarrollo 20122015: "Medellín, un hogar para vida" aborda el tema de la economía solidaria en la línea tres, "Competitividad para el desarrollo económico con equidad", en el programa "Emprendimiento y desarrollo empresarial social y solidario", cuyo propósito central es el siguiente:

Apoyar integralmente las iniciativas de emprendimiento empresarial y de innovación social productiva pertenecientes a la economía social y solidaria de Medellín. Mediante la creación e implementación de instrumentos que contribuyan al fortalecimiento de la estructura productiva de la ciudad en sus zonas urbanas y rurales que ayuden a generar trabajo decente $e$ ingresos para las personas emprendedoras y empresarias, buscando el acceso a oportunidades de desarrollo económico y social incluyente que favorezcan la disminución de la inequidad y las desigualdades (Alcaldía de Medellín, 2012, p. 220).

Se evidencia que este tipo de iniciativas responden al propósito de la Administración Municipal de lograr la consolidación de una cultura de emprendimiento solidario en la ciudad, para lo cual se dispuso, como mecanismo de intervención e indicador para medir el cumplimiento, el fomento y apoyo a la creación, el fortalecimiento y la consolidación de las UPA. Una forma asociativa se define de este modo:

Grupo mínimo [de tres o más personas según la forma de la organización y exigencia de la ley $\left.^{3}\right]$ que se unen para desarrollar una actividad económica empresarial sin ánimo de lucro, a través de la producción de bienes y servicios competitivos en el mercado, que permitan la generación de ingresos para la reinversión o la distribución equitativa de los excedentes económicos generados y la creación de empleos dignos, buscando la autosostenibilidad, la sustentabilidad de la misma y el beneficio para sus asociados y la comunidad de la cual hacen parte (Alcaldía de Medellín, 2008b, p. 1).

Para impulsar la creación de UPA se contemplan diversos beneficios, como brindar acompañamiento y orientación permanente; apoyo en materia administrativa, legal, contable, comercial y publicitaria; capacitación permanente con la posibilidad de realizar un diplomado en desarrollo empresarial para quienes conforman la idea de negocio; participación en ferias y eventos, y fortalecimiento de las UPA consideradas viables.

3 La UPA se pensó inicialmente como una asociación de 10 personas; en el 2008 se redujo el requisito a 5 personas, y en 2015 el requisito del mismo programa de Economía Solidaria fue de tres o más personas, según la forma de la organización y la exigencia de la Ley. 


\section{Economía solidaria desde la política pública}

Por supuesto, analizar el concepto de economía solidaria lleva a cuestionarse acerca del modelo económico imperante en la actualidad, el cual, a pesar de haber logrado extenderse a casi todos los rincones del planeta y arrojar resultados sorprendentes en términos de productividad, eficiencia, desarrollo tecnológico y generación de utilidades, no ha sido ajeno a duras críticas de diversos sectores, que incluso ponen en tela de juicio la pertinencia y sostenibilidad del sistema:

No puede negarse que el capitalismo, como sistema de producción, posee una formidable capacidad para producir bienes y servicios, aunque tampoco tanto como pregona; ahora bien, lo hace al precio de generar unos costes ecológi$\cos y$ sociales enormes. Como sistema de distribución, es cierto también que el capitalismo ha cubierto las necesidades básicas de una parte del planeta, pero a expensas de negarlas a la mayoría de la población mundial. La economía de mercado se ha revelado completamente incapaz de distribuir aquello que produce con un mínimo criterio, no ya de equidad sino simplemente de humanidad, y cuanto más se expande más aumenta la polarización entre géneros, clase y países (García, Vía y Xirinacs, 2006, p. 58).

Este planteamiento, al igual que muchos otros en torno al tema, ha sido reflexionado por teóricos y expertos en economía solidaria, tanto en América Latina como en países europeos. En América Latina se destacan, entre otros, Razeto (1993, 1994, 1998, 2000) en Chile, Coraggio (2008, 2012) en Argentina, Singer (2007) en Brasil y Zabala (2012) en Colombia.

Para Razeto (1993) no se trata de negar ni de reafirmar la economía de mercado, sino más bien de una propuesta que funciona bajo una nueva racionalidad económica, la cual hace necesario replantear el rol de la solidaridad en la economía, que no actúe desde afuera y con posterioridad, sino que se incorpore al desarrollo mismo del ciclo económico.

Al respecto debe considerarse que el espíritu de solidaridad es considerado uno de los principios de la economía solidaria, según la Ley 454 de 1998; no se trata solo de unirse a una causa común: se trata de cooperación y ayuda mutua hacia la conformación de organizaciones con sentido social, como bien lo expresa Sarmiento (2007):

Capital social con altos grados de confianza (comunidad no es solo una sumatoria de asociados) y riqueza e ingreso que facilite su distribución y formas de integración gremial, que a su vez sean espacios de construcción y formas participativas de la democracia (p. 85).

Por otra parte, Razeto (1994) plantea que esta nueva forma de hacer economía implica una nueva concepción del desarrollo que trascienda la medición de este, no solo en función de la expresión económica de una región, sino en busca de que los individuos puedan satisfacer necesidades básicas y de naturaleza superior con base en aspiraciones personales; que todos puedan ocuparse de forma digna y se haga uso eficiente de los recursos; que las relaciones interpersonales se desarrollen libres de explotación y conflictividad; que se logre un equilibrio ecológico y social, y que las personas cuenten con mejores condiciones de vida de las cuales puedan apropiarse con el desarrollo de competencias.

No obstante, es claro que para lograr tales propósitos: incorporar la solidaridad al desarrollo de la actividad económica y alcanzar un desarrollo más allá del mero crecimiento económico, se requieren profundas transformaciones sociales. Según Razeto (1994), sería erróneo buscarlas solo en el ámbito de la política, puesto que las dinámicas políticas se apoyan en la realidad y consideran grupos de interés y fuerzas existentes como pilares de la lucha por el poder; además, la política no 
crea realidades nuevas, sino que ordena las ya existentes.

Según Razeto (1994), en la sociedad se encuentra una gran energía transformadora proveniente tanto de aquellos que padecen circunstancias que debieran ser modificadas como de quienes, aun sin sufrir consecuencias, aspiran a cambiarlas movidos por ideas y valores de orden superior. En ese sentido, a partir de la misma sociedad civil pueden gestarse nuevas realidades para permitir esas transformaciones, no impuestas, sino por el acto mismo de ser y de actuar de otro modo, por el hecho de aportar a la sociedad una especial novedad.

Es preciso resaltar la importancia de las formas asociativas que se presentan como organizaciones sociales, pues estas, en razón del carácter organizacional, pueden tener mayor definición desde la conformación social, mayor potencialidad como sujeto y actor de un proceso de construcción económica de solidaridad, y cierta capacidad para ir a la vanguardia y ser orientadoras de procesos más amplios, en cuanto a la organización social y popular se refiere (Razeto, 1993).

Según este autor, estas organizaciones surgen en los sectores sociales más desfavorecidos, son conformadas por un grupo reducido de personas que logran conocerse entre sí, responden a las principales características de las formas organizativas, son de carácter económico, buscan generar cambios, operan bajo valores y principios solidarios, son democráticas, autogestionarias y participativas, combinan la actividad económica con otras de diversa índole, pretenden diferenciarse de las organizaciones predominantes en procura de una sociedad mejor y más justa y combaten el aislamiento y la marginación con trabajo coordinado y redes que les permitan potenciar y ampliar el alcance.

Las organizaciones con sentido social generan movilidad social, con lógicas de pensamiento y sentimientos abiertos; son flexibles, abiertas al cambio permanente, integran saberes populares y científicos en diferentes disciplinas de acuerdo con el contexto, lo que implica una reflexión constante sobre el modo de proceder, generar redes de trabajo con grandes vínculos a sistemas académicos, sociales, políticos y empresariales; redes que aborden el estudio de la realidad.

Es importante aclarar que lo expuesto por Razeto (1993) en torno a la sociedad civil como principal generadora de transformaciones sociales no implica una renuncia o negación de la política como elemento constitutivo de ese proceso de reforma y construcción de nuevas realidades; por el contrario, resulta indispensable que los actores políticos generen condiciones propicias para la aparición y el fortalecimiento de esos emprendimientos sociales.

Por su parte, Singer (2012) concibe la economía social y solidaria como una nueva forma de producir que se logra en forma cooperativizada, con la propiedad y la gestión colectiva de los medios de producción. Con relación a las políticas en mención, señala que ellas están en un contexto capitalista generador de tensiones, pero también que ellas conllevan objetivos educativos, por cuanto se ocupan de difundir la realidad de la economía social solidaria y la de los emprendimientos que les son propios. Argumenta también que estas intencionalidades educativas se hacen visibles porque las políticas públicas buscan transmitir conocimientos a trabajadores que ven en este tipo de economía una opción para la sobrevivencia humana:

As políticas de ESS têm freqüentemente como objetivos: 1) transmitir conhecimentos a trabalhadores e trabalhadoras que possam estar interessados em optar pela ESS, para habilitá-los a fazer esta opção conscientes das vantagens e desvantagens que ela implica; e 2) capacitar as pessoas já decididas a tentar a sorte na EES a dar os passos necessários a uma inserção efetiva na ESS seja mediante a associação com outros trabalhadores que fazem a mesma opção para formar novos empreendimentos solidários, ou seja pela entrada em 
empreendimentos solidários já em funcionamento (Singer, 2012, p. 29).

Advierte Singer (2012) que la economía social y solidaria es una de las estrategias que deben fomentarse para la reducción de la pobreza y el desarrollo de las economías nacionales; indica que la mejor vía para ello es la formulación de políticas públicas que proporcionen argumentos para el desarrollo de procesos asociativos entre la población trabajadora, al tiempo que resaltan la opción de la propiedad y administración colectiva de los medios de producción y el servicio de los sistemas financieros solidarios, lo que hace posible emprendimientos productivos de carácter cooperativo y autogestionado.

Desde la experiencia del Brasil se indica que la construcción de estas políticas públicas debe estar sometida a un proceso continuo de reconstrucción y evaluación, siempre en la perspectiva de mejoramiento, y que con la formulación de dicha política lo que debe pretenderse es que esta presente soluciones a las problemáticas que otras políticas no han podido resolver. La formulación debe ser entonces el resultado de la aplicación de conocimientos especializados, y teniendo en cuenta que el horizonte es la transformación socioeconómica, los resultados deben estar marcados por la cohesión y coherencia:

Para garantir esta consistência é indispensável que o órgão encarregado da ESS disponha de duas fontes contínuas de informações: uma sobre o que está acontecendo no movimento da ESS (no singular ou no plural) e outra sobre o que está acontecendo na realidade sócioeconômica e política da própria ESS, enquanto parte integrante da realidade social e econômica do país (Singer, 2012, p. 38).

Desde Argentina, Coraggio (2008) realiza varios aportes a la discusión; para él, la economía social solidaria está basada en valores humanos y principios de solidaridad para el reconocimiento de la otra persona. Dicha economía incluye al conjunto de actividades y organizaciones de carácter comunitario, asociativo, cooperativo, mutualista y demás formas colectivas creadas para responder a las necesidades de empleo y de bienestar de los pueblos, así como a movimientos ciudadanos orientados a democratizar y transformar.

Con relación a las políticas públicas para la economía social y solidaria, Coraggio (2012) señala que estas requieren un modelo específico para producción y apropiación del conocimiento sobre el tema, con desarrollos conceptuales y teóricos de referentes como solidaridad, eficiencia y economía popular.

Para el caso de Colombia, son importantes los aportes de Zabala (2012), que, refiriéndose a las orientaciones para una política pública en la perspectiva del desarrollo del cooperativismo y la economía solidaria, hace algunas propuestas que contribuyen a mejorar la articulación entre la economía solidaria y los procesos de desarrollo socioeconómico del país. Estas propuestas están relacionadas con reformas, ajuste o formulación de nuevas leyes básicas; reformas a disposiciones legales y actos administrativos; disposiciones legales generales para una política pública de fomento local y orientaciones para una política pública de fomento tributario.

Asimismo, es importante señalar que en Colombia el Centro de Investigaciones del Cooperativismo (Cenicoop) y la Confederación de Cooperativas de Colombia (Confecoop) (2012) han propuesto orientaciones para un adecuado planteamiento de las políticas públicas para el sector cooperativo y solidario. Al respecto, señalan:

Una política pública requiere del acompañamiento de la gestión coordinada, eficiente y de calidad para que haya impacto socioeconómico en las regiones. [...] El tema de desarrollo empresarial debe ir de la mano de la formulación de la política pública, precisamente para lograr el desarrollo que requieren las estructuras empresariales de la comunidad. 
Frente a los retos que impone el mercado, un buen desarrollo de asistencia técnica y la posibilidad de desarrollar una gestión eficiente en su implementación es clave para el éxito de esas políticas (pp. 12-13).

Igualmente, en Colombia el Ministerio Público, sobre la base de una evaluación del desenvolvimiento de las políticas públicas en los últimos años, señala un reto fundamental:

Es el momento que los actores de las políticas públicas hacia las cooperativas presenten opciones realmente alternativas en lo social, económico y político. Por lo tanto, ante el silencio de los actores tradicionales el enfoque de esas políticas dependerá sobre todo de los mismos cooperativistas, de nuevos líderes gremiales y los funcionarios públicos vinculados $y$ concientizados por y para el sector; pero también de las mismas comunidades de base, de las cooperativas locales organizadas, de los líderes no vinculados a organizaciones pero con legitimidad local (Procuraduría General de la Nación, 2012, p. 299).

Al hacer la articulación entre el concepto de política pública y el de economía solidaria y las prácticas locales, la investigación encontró que en Medellín se han dado pasos importantes para la creación de un marco legal y normativo, posibilitador de formas asociativas. Es el caso de la adopción de la Política Pública de Economía Social y Solidaria por parte del Concejo de Medellín (2011), con el Acuerdo 41 de 2011, que en el artículo 2 establece como destinatarios de la política pública a "categorías de organizaciones solidarias que por su objeto social y prácticas se identifican en la producción y comercialización de bienes y servicios como empresas sin ánimo de lucro".

En relación con la creación, el fortalecimiento y la consolidación de las UPA, la investigación encontró que gran parte del financiamiento se consigue a partir del Presupuesto Participativo, que en la ciudad es considerado como "eje articulador de la participación de la comunidad", al aplicar la Política Pública de Economía Social y Solidaria. Esta última, según Gómez et al. (2012), tiene que ver con una parte del presupuesto que la Administración Municipal asigna a la comunidad, con la participación democrática de las personas para formular y poner en marcha los planes de desarrollo para las comunas y corregimientos, decidir la destinación de los recursos asignados, participar de manera democrática en la construcción del futuro de la ciudad, brindar un espacio de socialización a distintos grupos sociales, con inclusión de las minorías y de las personas en condición de vulnerabilidad.

\section{Emprendimiento solidario y desarrollo humano en articulación con la Política Pública de Economía Social y Solidaria}

Es importante incluir en la reflexión el desarrollo humano y el emprendimiento solidario, toda vez que las Políticas Públicas de Economía Social y Solidaria en Medellín han sido planteadas desde un enfoque de emprendimiento social solidario y desarrollo humano, lo cual se constituye en uno de los fines de la intervención. La Unidad Administrativa de Organizaciones Solidarias (2013) concibe el emprendimiento social y solidario de este modo:

Manera de pensar, sentir y actuar creativamente, orientada a la generación de bienestar social calidad de vida y valor para el individuo y su comunidad que le permite desarrollar proyectos socio económicos en actuación cooperativa y en relación con el entorno. [...]

Disposición de un grupo de personas para aportar sus habilidades en la creación de nuevas ideas y proyectos de carácter colectivo, para el bienestar económico y social de los integrantes del grupo o de la comunidad en general, a través de la gestión y autonomía de los recursos necesarios (p. 37). 
Este tipo de emprendimiento, entonces, se relaciona con una "modalidad de organización económica y de trabajo, a la cual, y guiados por los principios de autogestión, cooperación, eficiencia y viabilidad, acuden los sujetos sociales que tienen como única herramienta su fuerza de trabajo" (Arboleda y Zabala, 2011, p. 80). Con el emprendimiento solidario se generan empresas solidarias, es decir, "formas de organizar recursos materiales y humanos, para satisfacer necesidades y lograr fines sociales por medio de un objetivo económico, de acuerdo con una forma diferente de hacer economía y de entender el desarrollo" (Unidad Administrativa de Organizaciones Solidarias, 2013, p. 37).

Los grupos de personas que forman parte de las empresas solidarias sobresalen en las comunidades por aplicar la solidaridad para organizar actividades de producción, distribución, circulación y consumo de bienes o servicios. Igualmente, aplican la cooperación y la autogestión para el beneficio de las organizaciones, toman decisiones de manera participativa y revierten esas decisiones en beneficio de las comunidades. Por lo tanto, los emprendimientos sociales y solidarios se caracterizan desde sus generalidades por un objeto social con arraigo en un territorio, por constituir una novedad que transforme y por desarrollar procesos autogestionarios, participativos y sostenidos, lo que se convierte en retos para las administraciones municipales al generar la creación, el fortalecimiento y la consolidación de ese tipo de emprendimientos.

Por su parte, el desarrollo humano, según los expone el Programa de Naciones Unidas para el Desarrollo (PNUD) (2008), hace referencia al proceso mediante el cual se buscan "ampliar las opciones que tienen las personas para llevar la vida que valoran, $[. .$.$] comparte una visión común$ con los derechos humanos. La meta es la libertad humana" (p. 1). Este planteamiento llama la atención sobre otro concepto de suma importancia: la libertad, el cual supone la facultad de la persona para tomar decisiones y actuar con autonomía en los diferentes aspectos de la vida, lo cual, desde la perspectiva de Mazzina (2007), "constituye la esencia de las relaciones sociales, los cimientos de una sociedad" (p. 32).

Sen (2010) no solo coincide con lo anterior a partir del análisis conceptual de la libertad, sino que va más allá y desarrolla esta idea en lo que denomina el "enfoque de las capacidades", donde plantea que el desarrollo humano debe evaluarse desde la óptica de lo que un individuo puede en realidad ser o hacer, es decir, de funcionamientos. Ello implica hacer uso de las propias capacidades, que están relacionadas con la posibilidad real de elegir y actuar de un modo determinado en los diversos ámbitos en los que se desenvuelve.

Lo anterior deja entrever que si bien la libertad constituye el eje del desarrollo humano, los individuos deben contar con unas condiciones que les permitan ejercer dicha libertad; dicho de otro modo, no es suficiente con que una persona pueda elegir el modo de vida que considere más conveniente, sino que pueda materializar esa elección.

No obstante, cabe aclarar que esas condiciones no están limitadas solo a contar con mayores recursos económicos, puesto que, como lo plantean Arteaga y Solís (2005), al analizar el tema de las políticas públicas de economía social y solidaria, la mejora en los indicadores de desarrollo no se percibe directamente en las personas; se trata de un proceso que contiene diferentes estrategias y diferentes actores que actúan de manera articulada $y$, por ende, es preciso abordar el mejoramiento de las condiciones de vida desde una perspectiva más integral.

Nussbaum (2000), por ejemplo, propone una lista de capacidades humanas centrales que deberían ser garantizadas y potenciadas para lograr el desarrollo de todo ser humano; estas incluyen vida, salud, integridad corporal, sentidos, imaginación, pensamientos, emociones, razonamiento práctico, afiliación con respecto a los demás y a sí mismos, relacionamiento con otras especies y control sobre el entorno de cada uno, tanto en el ámbito político como material. Esta lista, si bien no puede considerarse definitiva, por cuanto está supeditada a modificaciones de acuerdo con la cultura, las creencias y las circunstancias particulares 
de las comunidades, sí proporciona una visión del amplio rango de factores que han de tenerse en cuenta para poder hablar de un desarrollo humano que pueda considerarse integral.

De igual manera, producto de este análisis, puede intuirse que el Estado tiene la posibilidad de potenciar o restringir el desarrollo de las personas, al generar condiciones necesarias para garantizar subsistencia, seguridad, educación, salud, empleo, expresión y participación de los ciudadanos; para ello, se desarrollan diversas iniciativas orientadas a mejorar las condiciones de vida de la población más necesitada y vulnerable.

En ese propósito de generar un entorno propicio para avanzar en el campo del desarrollo humano, Arteaga y Solís (2005) coinciden en la necesidad de implementar nuevos paradigmas sobre la forma en la que funcionan las sociedades actuales; estos implican fortalecer la democracia y la participación ciudadana como corresponsables del bienestar de la población, avanzar hacia una verdadera equidad de género en diferentes ámbitos, potenciar las capacidades de los individuos, adoptar un nuevo concepto de Estado que trabaje de manera mancomunada con el sector privado y la sociedad civil y que integre los servicios públicos y privados, y pasar de un Estado proveedor de servicios a uno que promueva y vele por la equidad y calidad de estos.

Por lo anterior, desde la Política Pública de Economía Social y Solidaria se tiene la intención de un desarrollo humano integral, un desarrollo de las personas y para las personas con generación de oportunidades económicas para todos, enfoques participativos en diferentes etapas de desarrollo y con diferentes opciones humanas. Estos planteamientos permiten hablar también de la economía solidaria como alternativa de desarrollo, pues, en consonancia y derivado de esta nueva economía, se propician acciones orientadas por un nuevo paradigma del desarrollo. Desde la perspectiva de Razeto (2000), este paradigma incluye el desarrollo humano y tiene varias implicaciones:
Construir una teoría del desarrollo que no contradiga sino que prolongue coherentemente la concepción de mercado y del mejor funcionamiento de la economía en su conjunto, mediante una visión dinámica de su organización en el tiempo; [...] de elaborar una concepción del desarrollo que no niegue sino que profundice la necesidad de transformación de la economía, integrando entre ambos conceptos el de su perfeccionamiento en el tiempo y [...] de formular una teoría del desarrollo que no solo considere las variables ecológicas y humanas, sino que entienda la ecología, el medio ambiente, la integración social y el crecimiento humano como elementos constitutivos centrales del desarrollo económico (p. 159).

\section{El empleo en la política pública de economía solidaria}

En este análisis es necesario establecer diferencias entre lo que se conoce como empleo decente, trabajo decente y trabajo digno:

- El empleo decente se relaciona con aquellos casos en los que no solo se genera el empleo, sino también ingresos dignos. Allí las personas aceptan las condiciones del empleo y la remuneración (Personería de Medellín, 2014). Cabe aclarar que el empleo decente incluye protección social en relación con salud, riesgos y pensiones, además de otros derechos laborales como el de libre asociación (Salgado et al., 2015).

- El trabajo decente es un concepto universal referido en los derechos humanos y en convenios laborales abordados desde la Organización Internacional del Trabajo (OIT) (Salgado et al., 2015).

- El trabajo digno es un concepto utilizado en la normatividad colombiana; al igual 
que el empleo decente, incluye aspectos como salud, pensiones, riesgos y otros derechos laborales (Salgado et al., 2015).

Según Álvarez y Loaiza (2015), en esta ciudad se ejecutan simultáneamente dos políticas públicas que le tributan al empleo decente: la política Pública de Economía Social y Solidaria y la Política Pública de Generación de Empleo Decente, contempladas en el Acuerdo 41 de 2011 (Concejo de Medellín, 2011) y el Acuerdo 64 de 2013 (Concejo de Medellín, 2013). Según Álvarez y Loaiza (2015), "los modelos de operación del programa de Economía solidaria de Medellín combinan los dos elementos contenidos en ambas Políticas Públicas, trabajos dignos y empleos decentes que mejoren los niveles de equidad de la ciudad".

Igualmente, el Plan de Desarrollo 2012-2015 habla del fomento del trabajo decente, lo cual implica asumirlo tanto en los estudios previos como en el modelo de operación del programa de Economía Solidaria (Alcaldía de Medellín, 2012).

\section{METODOLOGÍA}

La metodología utilizada en el proyecto de investigación está relacionada con el enfoque cualitativo interpretativo; utiliza como técnica entrevistas semiestructuradas a informantes clave, realizadas entre el 14 y 24 de julio de 2015. Para este artículo se seleccionaron, por criterio de UPA exitosas, 11 beneficiarios que cumplían el rol de representantes legales en organizaciones intervenidas en el programa "Economía Solidaria", contenido en la línea tres de los planes de desarrollo 2008-2011 y 2012-2015 de la Alcaldía de Medellín. Como la investigación realizó una evaluación de efectividad de la Política Pública de Economía Solidaria, al testimonio de cada beneficiario se le asignó un código alfanumérico, iniciado con la letra $b$, para salvaguardar la confidencialidad.

La información fue analizada mediante construcción categorial resultante de la revisión teórica y conceptual relacionada con el objeto de estudio y de la información generada en el trabajo de campo. Las siguientes son las categorías definidas por el grupo investigador: origen de las UPA, condiciones socioeconómicas de los integrantes de la base asociativa, crecimiento de las UPA, formalización y sostenibilidad, estructura organizacional y cadena de valor, capacitación, desarrollo de actividades, empleo, relacionamiento e impacto medioambiental. Para el procesamiento de los datos se empleó el software Atlas.Ti 6.2 .

\section{DISCUSIÓN Y RESULTADOS}

\section{Origen de las UPA}

Teniendo en cuenta que el apoyo brindado por la Alcaldía de Medellín para la creación, el fortalecimiento y la consolidación de las UPA busca el mejoramiento de las condiciones de vida de los sectores sociales más desfavorecidos y en condición de vulnerabilidad, es necesario analizar el contexto en el cual surgieron estas iniciativas. La investigación pudo corroborar que entre los principales aspectos que motivaron a las personas a conformar las UPA está la posibilidad de percibir mayores ingresos, con el fin de garantizar la subsistencia y lograr una mayor independencia económica que les permitiera superar la falta de recursos y la inestabilidad laboral que padecían.

De igual manera, otra de las motivaciones está relacionada con el aprovechamiento de oportunidades brindadas por la Alcaldía de Medellín en convocatorias y concursos realizados, el apoyo de los Centros de Desarrollo Empresarial Zonal y la participación en el componente de Presupuesto Participativo, las cuales, según lo manifestado por los mismos participantes, ejercieron importante influencia en la formulación y puesta en marcha de las iniciativas.

Lo anterior deja entrever que la aplicación de la política pública ha tenido eco en la comunidad y ha logrado incentivar la participación ciudadana, lo cual permite señalar, a la manera de Coque (1999), que "en el entorno actual resultan ineludibles los proyectos de desarrollo que 
fomenten el pequeño emprendimiento y aún más el microemprendimiento, basado en la participación socioeconómica de todos los agentes implicados" (p. 124).

Cabe destacar el hallazgo de otros motivos subyacentes a la conformación de las UPA, que exteriorizan un sentido social y de apropiación orientado a transformar la realidad social con acción directa; tales propósitos comprenden la generación de oportunidades de empleo para los miembros de la comunidad, la satisfacción de alguna necesidad e incluso la promoción del desarrollo colectivo. Ejemplo de lo anterior puede verse en los testimonios de los beneficiarios: "[Hay que] hacerle entender a las personas que el campo es algo rentable, [...] retener las personas campesinas para que no dejaran sus tierras abandonadas y fueran a la ciudad, debido al mal manejo de sus cultivos" [b49]; su pretensión es "crear espacios de formación para la comunidad que genere un ingreso a las familias y un mejor manejo del tiempo libre" [b25]; "Nosotros tenemos un programa muy bueno para la gente. La UPA se ha convertido en un pretexto para que todos los sábados trabajemos hasta las 2-3 de la tarde, enseñándole a las personas a manejar una máquina, para hacer cualquier trabajo manual o alguna cosa, en su propia casa" [b40].

\section{Condiciones socioeconómicas de los integrantes de la base asociativa}

Las características demográficas muestran la vinculación de personas con diversos perfiles, pero develan dos realidades que facilitan el dimensionamiento del impacto social de estas iniciativas: la vinculación de grupos sociales minoritarios en condición de vulnerabilidad (mujeres cabeza de familia, adultos mayores, personas en condición de discapacidad, población campesina, madres comunitarias) y una alta participación de personas con niveles básicos de educación alrededor de este tipo de emprendimientos.

Asimismo, la investigación pudo establecer que alrededor de la mitad de las UPA apoyadas en el programa Economía Solidaria fueron conformadas por trabajadores informales, mientras en los demás casos se originaron a partir de organizaciones sociales (corporaciones, juntas de acción comunal, asociaciones y cooperativas); este hecho resulta bastante significativo al considerar lo expuesto por Razeto (1993) en torno al papel de este tipo de organizaciones como impulsoras de nuevas realidades transformadoras. Esta situación puede leerse también en la descripción que hace Gaiger (s. f.):

Los emprendimientos económicos solidarios abarcan diversas modalidades de organización económica, originadas en la libre asociación de los trabajadores, con base en principios de autogestión, cooperación, eficiencia y viabilidad. Aglutinando a los individuos excluidos del mercado de trabajo, o motivados por la fuerza de sus convicciones, y en búsqueda de alternativas colectivas de supervivencia, los emprendimientos económicos solidarios llevan a cabo actividades en los sectores de la producción o de la oferta de servicios, de la comercialización y del crédito (p. 229).

\section{Crecimiento de las UPA}

Al indagar por el crecimiento obtenido a partir del apoyo del programa, expresado en aumento de ingresos percibidos, capacidad operativa y captación de clientes, se pudo establecer que aquellas conformadas por personas que antes laboraban en condiciones de informalidad reportan los mayores niveles de crecimiento, mientras las originadas a partir de corporaciones resultan ser las de menor progreso en ese sentido. Se toman como evidencia los siguientes testimonios:

En esta gran idea de economía solidaria [...], la cual se ha venido trabajando con bastantes organizaciones de la comuna, muchos integrantes éramos informales; ahora las organizaciones con el apoyo 
han quedado muy bien equipadas, con una muy buena maquinaria, muy buena capacitación y también con unas ayudas en materia prima suficientes para que una empresa despegue hacia un futuro mejor. Este es un recorrido bonito que ha tenido la comuna 2, y cuando nace Economía Solidaria nosotros como líderes analizamos, metemos la acción comunal, el presupuesto participativo [b01].

Nosotros hemos hecho inversión social, tenemos procesos sociales en nuestra comuna y organización, es decir, ya éramos organización social, contrario a otros compañeros, con la conformación de la UPA, yo siento que hay retroceso en el crecimiento de la organización, o mejor dicho, hemos crecido menos. Nosotros no dependemos de P. P. [b48].

La anterior situación planteada por los beneficiarios resulta aún más llamativa si se tiene en cuenta que las UPA conformadas por personas que antes trabajaban en la informalidad soportan una mayor carga económica. Esto puede verse, por ejemplo, en el tipo de propiedad sobre el inmueble de funcionamiento, puesto que entre las creadas por personas que antes se desempeñaban en la informalidad predomina la figura de arriendo, al igual que en el caso de las cooperativas y asociaciones; mientras que la mayor parte de las surgidas de corporaciones operan en inmuebles propios.

Vale la pena cuestionarse acerca de la efectividad del apoyo proporcionado por la Alcaldía de Medellín para potenciar el crecimiento de estas formas asociativas, con independencia del nivel de desarrollo, por cuanto estos datos podrían mostrar la existencia de un mayor grado de dificultad para generar crecimiento en aquellas soportadas por organizaciones sociales con un aparato productivo establecido. Es importante precisar que si bien la mayor parte de las UPA valoran de manera positiva el apoyo recibido, la información obtenida indica que el otorgamiento de este no presenta diferencias en función de las características y circunstancias propias, y en algunos casos se ve entorpecido por la falta de continuidad de los cooperantes, demoras en la entrega de las ayudas e insuficiente control y seguimiento de la destinación de estas.

La supervivencia de las UPA constituye un factor crítico de éxito $y$, por tanto, un reto enfrentado por la Alcaldía de Medellín, máxime si se tiene en cuenta que según la Cámara de Comercio (2014) cerca del $30 \%$ de las empresas de la región desaparece entre el primer y el tercer año. Frente a esta realidad, al menos en el caso en estudio, las medidas adoptadas para contrarrestarla han arrojado resultados positivos, por cuanto todas las UPA participantes en este estudio permanecen activas y han logrado reducción paulatina de mortalidad.

\section{Formalización y sostenibilidad}

Todos los representantes han sido impulsados en la formalización, fueron capacitados en materia legal, complementada con acompañamiento, asesoría e incluso apoyo pecuniario en los trámites aplicables. Las UPA fortalecidas y consolidadas están en proceso de formalización o ya formalizadas. Esta es una de las condiciones planteadas por Singer (2007) como fundamental para que la economía solidaria logre la expansión como actividad económica:

No hay, en principio, ningún tipo de producción y distribución que no pueda ser organizado como emprendimiento solidario; [...] para que esta hipótesis se haga realidad en los diversos países es necesario garantizar las bases de sustentación para la economía solidaria. Las más importantes son las fuentes de financiación, redes de comercialización, asesoramiento técnico científico, formación continua de los trabajadores y apoyo institucional y legal de parte de las autoridades gubernamentales (p. 13). 
El siguiente testimonio avala el estado de formalización de las UPA al momento del estudio:

Todas las UPA de fortalecimiento y consolidación estamos legalizadas o estamos en proceso de hacerlo; es que eso es una exigencia desde los requisitos del concurso, pero con eso no es suficiente, [...] montamos empresas, pero se nos van como el agua entre los dedos. ¿Qué nos pasa? Falta más sentido de pertenencia de empresas $y$ salir adelante con ellas, $y$ saber vender. [...] La Alcaldía debe pensar en que necesitamos más apoyo en el tema de sostenibilidad de esas empresas [b13].

Teniendo en cuenta el carácter económico de las UPA, es claro que no basta con formalizarse y subsistir: es necesario también lograr que sean sostenibles y competitivas en el mercado. En este apartado no se apreciaron avances significativos, aunque la asesoría y el acompañamiento brindados han procurado integrar elementos que permitan alcanzar estos propósitos; por ejemplo, mediante el desarrollo de marcas propias, como lo dice el siguiente testimonio: "Yo vivo feliz porque impulsaron nuestra propia marca, el problema es sostener la marca en el mercado; eso es muy duro, ahí creo que le hace falta a la Alcaldía" b51].

La investigación encontró carencia de elementos diferenciadores que aporten valor agregado y les permita integrarse y competir en el mercado. Este es un asunto que merece especial atención, teniendo en cuenta lo expuesto por la Cámara de Comercio (2011) respecto a que la calidad de un establecimiento productivo está dada, entre otros aspectos, por la capacidad de generar valor y ofrecer más y mejores bienes y servicios. Según lo anterior, la investigación intuye que la sostenibilidad de las UPA es un gran reto que enfrenta la Alcaldía con la aplicación de la Política Pública de Economía Social y Solidaria.

\section{Estructura organizacional y cadena de valor}

La estructura organizacional denota un alto grado de formalismo en la formulación mediante el establecimiento de cargos, niveles jerárquicos y áreas funcionales bien definidas; asuntos abordados desde el Plan de Negocios y apoyado por la Alcaldía, como lo expresan los beneficiarios:

Todo está en el papel, en el plan de negocio, pero en la práctica es más complejo, porque depende de las características de cada UPA [b10].

Los planes de negocio están muy organizados [...], pero en la práctica [...] no se aplican, las lógicas de desarrollo de las UPA no son coherentes con esos planes de negocio. Cogemos a partes de ese proyecto de plan de negocio, [...] no se puede vivir, hay que pagar un montón de cosas, hay que pagar a cuatro mercaderistas todos los días, todo ese tema que hay que estar vendiendo, que un recepcionista que está recibiendo. La mayor parte la hizo el operador, entonces no es real, es demasiado grande para nosotros. En la práctica es otra cosa, nosotros cumplimos unas responsabilidades de acuerdo con los contratos [b01].

Hemos recibido planes de negocios, [...] entonces ya la última vez les dije yo: "No, pues, entonces para qué más planes de negocios, para seguir allá acumulando y uno sin entenderlos, la práctica es otra cosa. [...] Uno al principio sueña con cosas muy grandes, y la palabra puede más, y el papel puede más que otras cosas; entonces la práctica lo va ubicando a uno también, a aterrizar cosas b48]. 
Cuando la investigación realizó un examen más minucioso, encontró que esas estructuras jerárquicas y las divisiones son mucho más difusas en la práctica, y muchos de los roles son compartidos por varios integrantes de las UPA. Se convierte entonces en un reto para la Alcaldía el hecho de hacer un acompañamiento más coordinado con las estructuras empresariales de las UPA y con mayores niveles de asistencia técnica, para que actúen frente a los desafíos que les imponen en el mercado; reto que también ha sido visibilizado en estudio realizado por Cenicoop y Confecoop (2012). Lo contario ocurre para el diseño de la cadena de valor, cuyos procesos no están estipulados y surgen de forma espontánea en el desempeño de las actividades, sin que medie un proceso formal de planeación y formulación de estos.

Lo anterior resulta un poco desconcertante, y al mismo tiempo genera interrogantes respecto a la aplicación de nociones administrativas a la estructuración de estos emprendimientos; asunto que se convierte en un reto para la Alcaldía de Medellín, al enfrentar procesos de capacitación empresarial solidaria en los que las personas efectivamente asuman las empresas sociales y solidarias en coherencia con los procesos de transformación social, que potencie capacidades críticas y reflexivas a la luz de principios solidarios.

Este aspecto de capacitación para que las personas asuman responsabilidad en los procesos organizacionales de estas UPA puede sustentarse en los aportes de Arboleda y Zabala (2011), cuando hablan de condiciones que se identifican como relevantes para el éxito de los emprendimientos solidarios:

El fomento y fortalecimiento de condiciones de autogestión y participación, no simplemente como un ejercicio actitudinal o de aceptación de una doctrina empresarial sino como un asunto de mayor incorporación en sus prácticas, buscando asegurarle a la gente continuidad en el trabajo, ingresos y participación en toma de decisiones (p. 93).

\section{Capacitación}

Todos los beneficiarios han recibido capacitación en materia de emprendimiento, capacitación administrativa, técnica, legal, contable, mercadeo, así como de buenas prácticas de economía solidaria; sin embargo, la investigación identificó deficiencias relacionadas con aspectos esenciales en la gestión empresarial solidaria, como el objeto social, la base asociativa, el proceso de formalización, los grupos de interés e incluso los principios del cooperativismo. A partir de esta situación podría intuirse que el aprendizaje ha sido en gran medida reactivo $y$, por ende, sugiere la necesidad de emprender acciones encaminadas a reforzar este proceso, algo que no resultará sencillo, teniendo en cuenta las carencias educativas de gran parte de la población vinculada, pero que sin duda se torna vital para el desarrollo de las UPA.

La capacitación empresarial solidaria se convierte en un reto para la aplicación de la política pública; una capacitación que reflexione sobre la creación, el fortalecimiento y la consolidación de las UPA en términos de generación de bienestar social y mejoramiento de la calidad de vida tanto para los individuos en particular como para la colectividad, es decir, organizaciones sociales hacia la conformación de empresas solidarias. Lo anterior se puede evidenciar con los siguientes testimonios:

Yo pienso que todo ese proceso que nos han dado de las capacitaciones, o no han sido suficientemente profundas, 0 cada vez que hay una persona que nos va seguir un proceso repite las mismas capacitaciones, siempre de mercadeo, la parte de contabilidad; pero no hay una cuestión profunda que le ayude a uno a resolver el problema con el cual uno está, de los pagos de impuestos. [...] Pero por sobre todo, que este es un negocio social y solidario, por tanto requeriría de mayor capacitación hacia los empresarial solidario [b47]. 
Si hay una formación suficiente en economía solidaria y en gestión empresarial, ¿cuál es el problema? Que cuando usted llega a buscar esa economía solidaria dentro de los mismos integrantes de la UPA, es difícil, generalmente son egoístas; hay que hacer un trabajo de liderazgo muy grande y es muy difícil entender eso de empresas sociales y solidarias, para que todos lo puedan aplicar [b40].

Entonces de qué le sirve a usted recibir una capacitación, si como su nombre lo dice, es economía solidaria; solidaria es ser solidarios con todos, nosotros no debemos ser solidarios solamente como unidad productiva. Entonces, no solo es ser solidario con los compañeros de la UPA, eso significa ser solidario con la comunidad donde funciona la UPA, para eso nos apoyaron [b55].

En este contexto, la Procuraduría General de la Nación (2012) sostiene:

Se requieren líderes formados y preparados, producto de las mismas [...] [organizaciones sociales y solidarias], pero con conciencia política y con visión nacional, más allá de las marcas y los intereses de pequeños grupos de poder [...]deberá tenerse en cuenta el cooperativismo [...] que resume en su filosofía y doctrina, un equilibrio entre lo económico y lo social [...] se hace necesario que el sector cooperativo y solidario, logre verdaderos niveles de integración y [formación], reconociendo la diversidad y heterogeneidad de este tipo de empresas, pero generando la unidad en los puntos de encuentro, [de tal manera que la aplicación de políticas públicas, con respaldo de una base social amplia, le dará al Estado mayor seguridad y legitimidad] (pp. 299-300).
En suma, es un reto para la Alcaldía de Medellín, desde los aspectos relacionados con la capacitación, el fortalecimiento de la filosofía y los postulados de la economía social y solidaria, como fuerza reparadora y viva de la sociedad, maltratada por décadas consecutivas, pero con la esperanza de una vida mejor.

\section{Desarrollo de actividades de las UPA}

Se pudo establecer que, en promedio, cada unidad productiva asociativa cuenta con entre cinco y seis integrantes; incluso, en muchos casos, más del mínimo exigido para la conformación. Es importante destacar que las que parecen tener mayor capacidad de generación de empleo son aquellas que han mantenido estable la base asociativa o han aumentado el número de integrantes, distinto a los casos de UPA, que han sufrido cambios en la base asociativa.

El hecho de mantener la misma base asociativa deja entrever un alto grado de compromiso con la iniciativa, aspecto indispensable para dar continuidad a esta, a pesar de las vicisitudes que puedan presentarse en este tipo de emprendimientos sociales. En este contexto, como lo expone Razeto (1993), los principales factores que promueven el desarrollo de actividades $y$, por tanto, el crecimiento de este tipo de economía son el trabajo y la cooperación.

La información obtenida muestra que las condiciones en el ambiente de trabajo favorecen altos niveles de identificación y satisfacción con el trabajo. Las relaciones entre los integrantes son definidas en términos bastante positivos y con frecuencia trascienden el ámbito laboral; se reconocen en cada individualidad, llegan a establecer fuertes vínculos de familiaridad entre ellos y trabajan unidos en torno a una identidad colectiva que surge a partir de ideas o experiencias de vida en común; de ahí que, en algunos casos, se expresen profundos sentimientos de inconformidad y discrepancia con quienes, por diversos motivos, decidieron desvincularse de la UPA. 
Se encontró una percepción muy positiva frente al aporte de las UPA para el mejoramiento de la calidad de vida de los integrantes; sin embargo, al caracterizar dicho aporte, se observa una contribución más allá de lo económico, por cuanto se evidencia que trabajan con esmero y empoderamiento, sabiéndose útiles, con más autonomía e independencia, mejoran la autoestima, eficacia personal y deseos de superación, y logran que este aporte se haga extensivo a los núcleos familiares, al sentirse partícipes y disponer de más tiempo para compartir.

Ejemplo de lo anterior puede verse en el siguiente testimonio: "La iniciativa empresarial se ha convertido en mi proyecto de vida, es lo mejor que me puede pasar para mi vida personal y profesional. [...] Mi familia está feliz de vernos felices y comprometidas con el desarrollo de la UPA" [b51]. Lo anterior evidencia un compromiso con las UPA, en función del desarrollo de actividades que generan equilibrio y felicidad humana.

La Procuraduría General de la Nación (2012) también mira la economía social solidaria con visión de grandes oportunidades, que aunque se presentan en momentos de turbulencias en el país, disponen de caminos en los que se puede y es necesario implementar estrategias de integración del sector, con la participación de las voluntades de todos los actores.

\section{Empleo en las UPA}

Visto desde cualquiera de las tres dimensiones contempladas en las consideraciones teóricas (empleo decente, trabajo decente o trabajo digno), la investigación no evidencia mayores resultados al respecto; sin embargo, los beneficiarios coinciden en que las UPA son espacios que los han dignificado como seres humanos, ya que están conscientes de que no solo pueden mejorar sus ingresos en el mediano y largo plazo, sino que al mismo tiempo pueden potenciar capacidades y autorrealizarse: "La UPA es mi proyecto de vida, es la fuente de inspiración para todos mis logros. [...] En la comunidad estamos muy felices [...] con la UPA" [b51].

Esta mirada del empleo desde crecimiento humano y dignificación del ser se hace visible en la obra de Razeto (1993), cuando argumenta que la economía de la solidaridad debe contribuir al desarrollo de la capacidad humana en términos de principios superiores, al buscar no solo la utilidad individual, sino también el bien común, con la satisfacción de necesidades colectivas. También plantea la dimensión espiritual, al permitir a las personas encontrar sentido a lo que hacen y viven en la cotidianidad. Esta consideración es avalada por la OIT:

Las empresas y organizaciones en la economía social y solidaria crean y mantienen empleos y medios de vida, amplían la protección social, fortalecen y amplían el diálogo social a todos los trabajadores y promueven la aplicación y cumplimiento de normas para todos. En estos tiempos de crisis e inestabilidad, la promoción de la economía social y solidaria, dentro del marco del Programa de Trabajo Decente, es una forma eficaz de promover la justicia social y la inclusión social en todas las regiones (Fontenea et al., 2011, p. IV).

Como se indicó, la investigación encontró que muchas UPA se conformaron por personas naturales, en tanto muchas otras lo hicieron por personas que estaban agrupadas en organizaciones sociales; sin embargo, todos los beneficiarios coinciden en que la principal motivación fue el hecho de unir esfuerzos para generar ingresos, que serán adquiridos en el mediano o largo plazo. Esta situación se puede evidenciar a partir de los siguientes testimonios:

Ahí comenzamos nosotros con una intensión de comuna, de cómo ayudar, porque es que la verdad el empleo ha sido duro en nuestras comunas, el empleo ha sido 
muy duro, porque nosotros tenemos allá $[. .$.$] rebusque, [. .$.$] empleados, [...]$ venteros ambulantes, $y$ lo otro es que ya todo mundo sabe cómo es la cosa pues. Entonces, viendo tanta necesidad y tanta gente joven y con ganas de trabajar, [...] nos presentamos [b01].

Hemos logrado reconocer que podemos ser cada vez mejores, o que a la vez hacemos un trabajo, que por ese trabajo nos pagan, y que de esos recursos que nos pagan cubrimos otras necesidades, y que realmente cuando logramos hacer un contrato, ya tenemos una solución a cosas personales o de familia; porque realmente antes [...] a uno le preguntaban: "¿usted qué hace?", y uno decía: "No, yo soy trabajador independiente"; entonces ahora a uno le preguntan: ¿usted qué hace?, y uno responde: "Yo trabajo en una UPA". "¿Usted trabaja con qué entidad?". Entonces uno responde: "Nosotros tenemos una Corporación y hacemos esto, hacemos aquello, y somos gente de la comunidad" [b25].

Que necesitábamos ya era más herramientas, necesitábamos saber cómo íbamos a trabajar; y ahora en este tiempo estamos luchando es cómo lo conseguimos [b01].

Nosotros todavía trabajamos de puro voluntariado [b48].

Los anteriores testimonios coinciden con lo expresado por Razeto (2000) respecto a la economía popular, como uno de los caminos que conducen al surgimiento y la consolidación de la economía de la solidaridad, en la medida en que se comienzan a gestar, en entornos sociales, iniciativas hacia el trabajo por cuenta propia; organizaciones económicas populares conformadas por grupos de personas que ingresan a las lógicas del sistema capitalista, donde pueden ser excluidas, lo que las obliga a buscar otras alternativas de ocupación que les permita generación de ingresos.

Igualmente, a estas prácticas socializadas por los beneficiarios puede encontrárseles perfecta sintonía con el pensamiento del propio Razeto (1998), cuando en la relación que el profesor establece entre el factor trabajo y el ser humano (que denomina factor comunidad o factor $C$ ) dice que lo que predomina en ello es la libre voluntad y la obra común, y que desde ahí "un modo de organización del trabajo [...] será un modo de organización hecho de manera tal que genere vínculos asociativos, vínculos comunitarios" (p. 42).

Cuando la investigación trató de profundizar sobre las características y los estilos de trabajo, se pudo constatar en estas UPA que, siendo pocas y habiendo enfrentado innumerables dificultades, en ellas existen formas de cooperación y ayuda mutua hacia el cumplimiento de objetivos comunes, participación democrática, trabajo en equipo, servicio a la comunidad; razones por las cuales han ganado un espacio en cada contexto donde se desempeñan.

Ahora bien, al indagar específicamente sobre empleos decentes, se escucharon los siguientes testimonios:

Yo genero 10, 12, 15 empleos y fuera de los mensajeros, por ahí 10 empleos semanales. [...] Yo pago por prestación de servicios; [...] es de lógica, muchachos, tengo muchos contratos, pero me los he buscado [b13].

Tenemos dos empleos, digamos que remunerados y justos, [...] y el otro que está arrancando, con un mínimo [...] el que está arrancando en la parte administrativa, es un compañero que es un sociólogo, [...] también vende; la otra persona es el compañero que es el representante legal, [...] él es el gerente y representante legal de la UPA; y yo soy la coordinadora a nivel nacional con las ventas [b10]. 
Tenemos tres empleos que se cubre todo, y tenemos en este momento cuatro personas más que nos colaboran, pero no se ganan ni el mínimo porque hay unas que solamente pulen y es muy difícil yo pagarle un mínimo a una persona que está puliendo únicamente; [...] entonces les pagamos un poquito mejor, pero no alcanza todavía, o nosotros no alcanzamos para pagarle a un pulidor, o al que nos hace los mandados, o así, para pagarles un mínimo todavía no alcanzamos. Estamos proyectados que para septiembre más o menos incluimos a la otra persona $[. .$.$] y que para diciembre$ más o menos tengamos la quinta [b40].

Pero entonces ya ahora si nos pusimos fue en organizarnos bien en forma, e hicimos todo lo posible por legalizar con calidad de vida a dos trabajadores fijos, con prestaciones sociales y todo lo que realmente se le debe a una persona, un trabajo digno [b41].

Ahora ya tengo dos vinculados a trabajo digno, o sea, con todas las prestaciones sociales; en sí, a nosotros nos faltaba algún poco para pagarles todo, porque les teníamos solo lo que era seguridad social, o seguridad de nosotros, de la empresa, riesgos profesionales y salud; ahora ya les estamos pagando lo que es la pensión y la Caja de Compensación [...] a dos en el centro de acopio, [...] ya los otros estamos es por la cooperativa, si tenemos todo [...] en sí somos seis personas [b41].

Los empleos que estamos generando son dignos, y nos ha servido muchísimo el hecho de que, hubiéramos establecido todo con la comunidad desde el principio, porque en este momento tenemos contratos es con empresas, con colegios, porque ellos exigen que se vinculen, exigen que las personas estén vinculadas a seguridad social, [...] a todas sus prestaciones [b45].

Nosotros tenemos seis empleos decentes, inicialmente éramos cuatro, no se estaba llevando como el buen manejo a los vigilantes que prestaban el servicio, con un contrato que no era el adecuado porque no se les pagaba seguridad social ni nada [...] y ya pues, hubo un acompañamiento frente a eso, y ya se les brindó, se les paga seguridad social [b47]).

Muchos de los beneficiarios exitosos son conscientes de que las UPA son empresas de economía solidaria, las cuales "se constituyen para satisfacer preferentemente necesidades aspiraciones y deseos de sus asociados y el desarrollo de obras de servicio comunitario"; asimismo, que una empresa de economía solidaria "es una organización que genera recursos económicos, con actividades socio empresariales, que no busca el enriquecimiento personal individual, sino mejorar la calidad de vida de todos sus asociados y de la comunidad" (Unidad Administrativa de Organizaciones Solidarias, 2013, p. 9); sin embargo, el proceso de generación de empleos decentes es lento.

Como puede verse, al revisar los retos enfrentados por la Alcaldía de Medellín con la aplicación de la Política Pública de Economía Solidaria, el campo del empleo decente es uno de ellos, por no decir el mayor. El trabajo decente es un pacto mundial que se debe contemplar a la hora de aplicar la política pública de economía solidaria, pero debe contar con el apoyo del Estado local, conscientes de las implicaciones que tiene para una empresa social y solidaria el mínimo de cumplimiento con las obligaciones laborales; por lo tanto, la brecha es aún grande y se requiere de acciones públicas intencionadas para dar saltos cualitativos en la economía solidaria como alternativa al desarrollo en la generación de trabajo decente e integral. 


\section{Relacionamiento de las UPA}

Cabe anotar que esta se da mediante la participación en muestras empresariales, ferias comerciales y actividades comunitarias, en las que pueden compartir experiencias y darse a conocer; sin embargo, no se evidencia una asociación productiva entre ellas, como lo plantea un beneficiario: "Hemos estado en ferias en plaza mayor y otros sectores de la comuna donde se participan en concursos con otras UPA, pero no hay un vínculo o relación laboral" [b10].

El asunto de las redes se convierte, por tanto, en otro aspecto significativo para la Alcaldía de Medellín desde el punto de vista de los retos. Una red en economía solidaria refiere indiscutiblemente a "los acuerdos de trabajo de grupos de personas, cuyo aspecto estratégico es la construcción de tejido social y solidario entre las organizaciones que la lideran" (Salgado, 2015, p. 301). Así también lo visualiza la Procuraduría General de la Nación (2012), al manifestar que la integración del sector debe ser entendida como "la creación de redes de prosumidores (productos y consumidores) de sus propios productos y servicios que sin importar marcas o lugares del país, todos los asociados tengan ventajas agregadas y visibles para estar y participar de los portafolios".

\section{Impacto medioambiental}

Puede decirse que existe más conciencia acerca del tema de la que podría pensarse, en vista de la necesidad de generar recursos económicos, manifestada en la adopción de medidas relacionadas con el manejo de los residuos como el compostaje, el reciclaje y la reutilización, así como la realización de actividades de voluntariado para la preservación de espacios naturales de sensibilización y trabajo con la comunidad, tal como relata un beneficiario: "Regalan bolsas a las personas del barrio, para que la gente pueda sacar las basuras y organizarlas" [b55]. No obstante, como ocurre con la mayoría de empresas tradicionales, los esfuerzos están más encaminados a la mitigación de los impactos generados que a evitar causarlos en el desarrollo de la actividad productiva.

Resulta pertinente tener en cuenta que frente al tema la Procuraduría General de la Nación (2012) manifiesta:

Si los grandes retos de la humanidad son: superar la recesión económica mundial, la seguridad alimentaria para hacer frente a los problemas de hambre de la población, el cambio climático con efectos en el agua potable, la bioenergía y la estabilidad en los precios de las materias primas, principalmente de alimentos se hacen necesarias políticas [públicas para el sector social y solidario en el ámbito agrario] (p. 301).

También resulta pertinente para la discusión la postura de la Organización de Naciones Unidas (ONU, 2014):

Desde el punto de vista de la protección del medio ambiente, del reto de separar el crecimiento del impacto medioambiental así como de la elaboración de transiciones económicas que sean verdes y equitativas, las organizaciones de ESS [economía social solidaria] cuentan con una importante y notable ventaja con respecto a las empresas convencionales. Carecen casi totalmente de la necesidad de externalizar costos medioambientales y sociales o el consumo de combustible como parte de las estrategias de maximización de los beneficios y competitividad. Estas organizaciones tienden, además, a tener una menor huella de carbono debido no solo a sus objetivos medioambientales sino también a la naturaleza de sus sistemas de producción e intercambio. Además, organizaciones como cooperativas forestales y grupos comunitarios de silvicultura pueden desempeñar un papel importante en la gestión sostenible de los recursos naturales, en particular 
en contextos donde estos representan recursos de uso comunitario (pp. IV-V).

Independiente de los indicadores de planes de desarrollo en términos de creación, fortalecimiento y consolidación de unidades productivas asociativas, la investigación encontró que es un reto para la Alcaldía de Medellín el compromiso de todos los actores involucrados para la presentación de alternativas reales en términos sociales, económicos y políticos; como también lo refiere la Procuraduría General de la Nación (2012), esos actores son cooperativistas, líderes gremiales, funcionarios públicos vinculados con el sector y las comunidades de base.

\section{Conclusiones}

Teniendo en cuenta los indicadores contenidos en los últimos dos planes de desarrollo de la ciudad de Medellín (2008-2011 y 2012-2015) para la creación, el fortalecimiento y la consolidación de Unidades Productivas Asociativas (UPA), la aplicación de la Política Pública de Economía Social y Solidaria en la ciudad se encuentra ahora frente a una nueva etapa que resultará decisiva para determinar el verdadero aporte a la superación de problemáticas sociales y generación de desarrollo equitativo e incluyente. Esto demandará ya no solo proporcionar las condiciones necesarias para el surgimiento de estas iniciativas, sino lograr su consolidación y hacer frente a importantes retos que se pueden ver en mayor detalle en el anexo 1.

\section{REFERENCIAS}

1. Alcaldía de Medellín (2004). Plan de desarrollo 2004-2007: Medellín, compromiso de toda la ciudadanía. Medellín: Autor.

2. Alcaldía de Medellín (2008a). Plan de desarrollo 2008-2011: Medellín es solidaria y competitiva. Medellín: Autor.

3. Alcaldía de Medellín (2008b). UPA Medellín, Unidades Productivas Asociativas de las Comunas de Medellín. Recuperado de http://www.ucn.edu.co/cisp-ucn/Paginas/que-es-upa.aspx

4. Alcaldía de Medellín (2012). Plan de desarrollo 2012-2015: Medellín, un hogar para la vida. Medellín: Alcaldía de Medellín.

5. Alcaldía de Medellín (2014a). Medellín en cifras. Recuperado de https://www.medellin.gov.co/irj/portal/ci udadanos?Navigation Target=navurl://b04f34aa77cfe4e63a58980e6d7c7b22

6. Alcaldía de Medellín (2014b). Indicadores Programa de Emprendimiento y Desarrollo Empresarial Social y Solidario, con corte a diciembre de 2014. Medellín: Autor.

7. Alcaldía de Medellín (2014c). Informe de Economía Solidaria. Medellín: Autor.

8. Álvarez, J. J. y Loaiza, R. (2015, 19 y 26 de agosto). Entrevista de O.A. Salgado Cañaveral, M. del S. Alzate Cárdenas y O. L. Arboleda Álvarez [audio]. [Coordinador del Área de Economía Solidaria-Secretaría de Desarrollo Económico y Coordinador de la Unidad de Planeación del desarrollo económico -Departamento Administrativo de Planeación]. Medellín: Fundación Universitaria Luis Amigó. 
9. Arboleda Álvarez, O. L. y Zabala Salazar, H. (2011). Condiciones clave para el éxito y sostenibilidad de los emprendimientos solidarios en Medellín. Semestre Económico, 14(28), 77- 94

10. Arteaga, C. y Solís, S. (2005). Necesidades sociales y desarrollo humano: un acercamiento metodológico. Ciudad de México: Plaza y Valdés.

11. Cámara de Comercio (2011). Análisis de las principales características de las empresas en Antioquia. Revista Antioqueña de Economía y Desarrollo (RAED), 2, 8-25. Recuperado de http://www.camaramedellin.com. $\mathrm{co} /$ site/Portals/0/Documentos/Biblioteca/raed-Numero-2-dfhfgh.pdf

12. Cámara de Comercio (2014). Informe de la Economía en Antioquia 2013. Revista Antioqueña de Economía y Desarrollo (RAED), 8, 8-51. Recuperado de http://www.camaramedellin.com.co/site/Biblioteca-virtual/ Estudios-economicos/Revista-Antioquena-de-Economia-y-Desarrollo-RAED.aspx

13. Centro de Investigaciones del Cooperativismo (Cenicoop) y Confederación de Cooperativas de Colombia (Confecoop) (2012). El cooperativismo y la política pública: un documento que busca proponer como herramienta el modelo cooperativo en beneficio de la comunidad. Bogotá: Autor.

14. Concejo de Medellín (2011). Acuerdo 41 de 2011, por medio del cual se adopta la política pública para la economía social y solidaria en el Municipio de Medellín. Recuperado de http://luisbernardo. com/2015/05/27/acuerdo-municipal-n-41-de-2011/

15. Concejo de Medellín (2013). Acuerdo 64 de 2013, por medio del cual se establece la política pública de trabajo decente en la ciudad de Medellín. Recuperado de https://www.medellin.gov.co/irj/go/ $\mathrm{km} /$ docs/pccdesign/SubportaldelCiudadano_2/PlandeDesarrollo_0_17/ProgramasyProyectos/2015/ PoliticasPublicasLocales/Shared\%20Content/Ācuerdos/ACUERDŌ64DE2013.pdf

16. Congreso de la República (1998). Ley 454 de 1998, por la cual se determina el marco conceptual que regula la economía solidaria, se transforma el Departamento Administrativo Nacional de Cooperativas en el Departamento Administrativo Nacional de la Economía Solidaria, se crea la Superintendencia de la Economía Solidaria, se crea el Fondo de Garantías para las Cooperativas Financieras y de Ahorro y Crédito, se dictan normas sobre la actividad financiera de las entidades de naturaleza cooperativa y se expiden otras disposiciones. Diario oficial, 43.357.

17. Coque, J. (1999). Industrialización en el entorno local a través de (sociedades) cooperativas. Revesco, Revista de Estudios Cooperativos, 868, 119-137.

18. Coraggio, J. L. (2008). La economía social y solidaria como estrategia de desarrollo en el contexto de la integración regional Latinoamericana. III Encuentro Latinoamericano de Economía Solidaria y Comercio Justo. Recuperado de www.coraggioeconomia.org/jlc/.../ponencia_jlc.doc

19. Coraggio, J. L. (2012). Economía social y solidaria: las relaciones entre conocimiento y políticas públicas. En J. L. Coraggio (Ed.), Conocimiento y políticas públicas de Economía Social y Solidaria problemas y propuestas (pp. 85-104) Quito: IAEN.

20. Departamento Administrativo Nacional de Estadística (DANE) (2015a). Medición del empleo informal y seguridad social. Recuperado de http://www.dane.gov.co/files/investigaciones/boletines/ech/ech_informalidad/bol_ech_informalidad_sep_nov15.pdf.

21. Departamento Administrativo Nacional de Estadística (DANE) (2015b). Indicadores del mercado laboral. Recuperado de http://www.dane.gov.co/files/investigaciones/boletines/ech/ech/bol_empleo_dic_14.pdf 
22. Fontenea, B., Neamtan, N., Wanyama, F., Pereira Morais, L., de Poorter, M., Borzaga, C. y Galera, G. (2011). Documento de trabajo 2011: economía social y solidaria: nuestro camino común hacia el trabajo decente. Montrea: CIF-OIT.

23. Gaiger, L.I. (2009). Emprendimientos económicos solidarios. Recuperado de http://wb.ucc.edu.co/institucional5/files/2011/08/emprendimientoseconomicosolidarios.pdf.

24. García, J., Via Llop, J. y Xirinacs, L. L. M. (2006). La dimensión cooperativa: economía solidaria y transformación social. Barcelona: Icaria.

25. Gómez, E., Vásquez G., Lenti, A., Franco, L. M., Herrera, G., Aguirre, G. y Giraldo R. (2012). Planeación participativa realidades y retos. Alcaldía de Medellín y Universidad de Antioquia.

26. Mazzina, C. (2007). ¿Qué es la libertad? Revista Laissez-Faire, 26-27, 32-44.

27. Muller, P. (2010). Las políticas públicas. Bogotá: Universidad Externado de Colombia.

28. Nassbaum, M. C. (2000). Women and human development: the capabilities approach. Cambridge: Cambridge University Press.

29. Organización de Naciones Unidas (ONU) (2014). La economía social y solidaria y el reto del desarrollo sostenible. Recuperado de http://unsse.org/wp-content/uploads/2014/08/Position-Paper_TFSSE_Esp1.pdf

30. Personería de Medellín (2014). Las Unidades Productivas Asociativas alternativa de empleo digno utopía o realidad (Versión 2-2014). Informe final de Investigación de la línea Económica de Planeación Local y Presupuesto participativo. Medellín: Autor.

31. Procuraduría General de la Nación (2012). Políticas Públicas y Cooperativismo en Colombia: 30 años de encuentros y desencuentros. Bogotá: Autor.

32. Razeto Migliaro, L (1994). Fundamentos de una teoría Económica Comprensiva: Libro tercero de Economía de la solidaridad y Mercado Democrático. Santiago de Chile: Ediciones PET.

33. Razeto Migliaro, L. (1993). Los caminos de la economía de solidaridad. Santiago de Chile: Vivarium.

34. Razeto Migliaro, L. (1998). Alternatividad y racionalidad de la economía solidaria. Medellín: Escuela Colombiana de Economía Solidaria.

35. Razeto Migliaro, L. (2000). Desarrollo, transformación y perfeccionamiento de la economía en el tiempo Santiago de Chile: Universidad Bolivariana.

36. Real Academia Española (RAE) (2014). Política. Recuperado de http://dle.rae.es/?id=Ta2HMYR

37. Salgado Cañaveral, O. A. (2015). Construcción de tejido social y solidario en la Red De Economía Solidaria De Antioquia -Redesol- Antioquia 2004-2011. VII Encuentro de Investigadores Latinoamericanos. Bogotá: Alianza Cooperativa Internacional.

38. Salgado Cañaveral, O. A., Arboleda Álvarez, O. L., Alzate Cárdenas, M., Peralta Robledo, G. B. y Pareja Mesa, M. L. (2015). Política pública de economía solidaria en el contexto de planeación local y presupuesto participativo de medellín 2008-2015: evaluación de su efectividad. Medellín: Editorial Artes y Letras.

39. Sarmiento Narváez, A. (2007). Hacia una política pública del sector solidario en Colombia. En O. Useche et al. (Comps.), Desarrollo, ciudadanía y cambio social: desafíos para las políticas públicas en Colombia. Bogotá: Anthropos. 
40. Sen, A. (2010). La idea de la Justicia. Bogotá: Tauros.

41. Singer, P. (2007). Economía Solidaria: un modo de producción y distribución. Recuperado de https://periferiaactiva.files.wordpress.com/2015/11/unidad-1-texto-9-economia-solidaria-paul-singer.pdf

42. Singer, P. (2012). Experiencias brasileñas en políticas públicas para a ESS. En J. L. Coraggio (Ed), Conocimiento y políticas públicas de Economía Social y Solidaria problemas y propuestas (1. e. ed.; pp. 27-39). Quito: Editorial IAEN.

43. Unidad administrativa de Organizaciones solidarias y Ministerio del Trabajo (2013). Cursos básico, medio y avanzado de Economía Solidaria. Recuperado de http://www.orgsolidarias.gov.co/?q=educaci\%C3\%B3n-solidaria/ herramientas-educativas/herramientas-virtuales/curso-de-econom\%C3\%ADa-solidaria.

44. Zabala Salazar, H. (2012). Políticas públicas para la internacionalización del cooperativismo. En J. F. Álvarez (Comp.), Cooperativismo e internacionalización (tomo II, pp. 77-79). Bogotá: Ministerio del Trabajo. 


\section{ANEXO 1}

Categorías de análisis y resultados en la experiencia de las UPA

\begin{tabular}{|c|c|c|c|c|}
\hline $\begin{array}{c}\text { Categorías de } \\
\text { análsis * }\end{array}$ & Retos & Acciones propuestas & Resultados** & Aprendizajes en el rol de los docentes \\
\hline \multirow[t]{2}{*}{ Creación de UPA } & $\begin{array}{l}\text { Generación de } \\
\text { un pensamiento } \\
\text { solidario para } \\
\text { la creación de } \\
\text { empresas de este } \\
\text { tipo en la ciudad. }\end{array}$ & $\begin{array}{l}\text { 1. Capacitar en Economía } \\
\text { Solidaria: se requiere } \\
\text { de una capacitación } \\
\text { que realmente genere } \\
\text { interiorización y } \\
\text { aplicación de este tipo } \\
\text { de economía en las } \\
\text { organizaciones que se } \\
\text { crean. } \\
\text { 2. Revisar } \\
\text { minuciosamente las } \\
\text { propuestas de ejecución } \\
\text { de la política pública, } \\
\text { de tal manera que se } \\
\text { generen procesos de } \\
\text { capacitación, donde } \\
\text { las personas se asocien } \\
\text { para el desarrollo de } \\
\text { actividades productivas } \\
\text { y/o de servicios basados } \\
\text { en la solidaridad. } \\
\text { 3. Diseñar e implementar } \\
\text { estrategias diferenciadas } \\
\text { para la capacitación, } \\
\text { de acuerdo con los } \\
\text { niveles de desarrollo } \\
\text { y particularidades } \\
\text { organizacionales, con el } \\
\text { fin de alcanzar niveles de } \\
\text { crecimiento significativos } \\
\text { que contribuyan al } \\
\text { fortalecimiento y } \\
\text { consolidación de este } \\
\text { tipo de organizaciones. }\end{array}$ & $\begin{array}{l}59 \text { personas } \\
\text { recibieron diplomado } \\
\text { en Economía } \\
\text { solidaria en el año } \\
2014 .\end{array}$ & \multirow[t]{2}{*}{$\begin{array}{l}\text { El aprendizaje está en el hecho de } \\
\text { aprovechar las oportunidades que el } \\
\text { Estado a través de la Administración } \\
\text { Municipal ofrece para la creación de } \\
\text { Unidades Productivas Asociativas, la } \\
\text { universidad debe generar estrategias } \\
\text { de acompañamiento para aumentar los } \\
\text { niveles de participación en la creación } \\
\text { de unidades productivas asociativas, de } \\
\text { tal manera que se construyan proyectos } \\
\text { sociales y solidarios que impacten } \\
\text { positivamente los contextos de actuación } \\
\text { de estudiantes y graduados, proyectos } \\
\text { orientados a pensar, sentir y actuar } \\
\text { creativamente hacia la generación de } \\
\text { bienestar social y desarrollo equitativo e } \\
\text { incluyente. }\end{array}$} \\
\hline & $\begin{array}{c}\text { Desarrollo de } \\
\text { competencias en } \\
\text { emprendimiento } \\
\text { social y solidario, } \\
\text { coherentes con } \\
\text { la potenciación } \\
\text { de empresas } \\
\text { que logren } \\
\text { finalidades sociales } \\
\text { y producción de } \\
\text { riqueza colectiva } \\
\text { como lo establece } \\
\text { el acuerdo } 41 \text { de } \\
2011 \text { del Concejo } \\
\text { de Medellín. }\end{array}$ & $\begin{array}{c}\text { Sensibilizar en } \\
\text { el desarrollo de } \\
\text { competencias } \\
\text { empresariales solidarias, } \\
\text { lo cual requiere del } \\
\text { establecimiento de un } \\
\text { pensamiento social } \\
\text { y solidario en las } \\
\text { organizaciones que se } \\
\text { crean. }\end{array}$ & $\begin{array}{l}8 \text { UPA recibieron } \\
\text { acompañamiento } \\
\text { para registro de } \\
\text { marca en el año } \\
2014,84 \text { personas } \\
\text { fueron formadas } \\
\text { técnicamente en } \\
\text { oficios en el año } \\
2014 .\end{array}$ & \\
\hline
\end{tabular}




\begin{tabular}{|c|c|c|c|c|}
\hline $\begin{array}{l}\text { Categorías de } \\
\text { análsis * }\end{array}$ & Retos & Acciones propuestas & Resultados** & Aprendizajes en el rol de los docentes \\
\hline \multirow[t]{2}{*}{$\begin{array}{c}\text { Fortalecimiento } \\
\text { de UPA }\end{array}$} & $\begin{array}{c}\text { Fortalecimiento } \\
\text { de procesos de } \\
\text { innovación que } \\
\text { estén orientados } \\
\text { a la generación } \\
\text { de valor agregado } \\
\text { y al aumento de } \\
\text { la productividad } \\
\text { y adaptabilidad } \\
\text { de las UPA, } \\
\text { contribuyendo así } \\
\text { al fortalecimiento, } \\
\text { autosostenibilidad } \\
\text { y competitividad } \\
\text { de estas, de modo } \\
\text { que puedan } \\
\text { integrarse con } \\
\text { éxito a la dinámica } \\
\text { económica. }\end{array}$ & $\begin{array}{c}\text { Revisar y ajustar el } \\
\text { modelo de operación } \\
\text { en la fase de } \\
\text { fortalecimiento, de } \\
\text { tal manera que se } \\
\text { mejoren los procesos } \\
\text { de innovación social al } \\
\text { interior de las UPA. El } \\
\text { proceso de fortacimiento } \\
\text { requiere mayor } \\
\text { acompañamiento técnico } \\
\text { y articulación en otras } \\
\text { dinámicas ciudad sobre } \\
\text { innovación. }\end{array}$ & \begin{tabular}{|} 
Con una línea base \\
de 9000 créditos \\
otorgados por \\
el Banco de las \\
Oportunidades, el \\
plan de desarrollo \\
2012 -2015 establece \\
una meta de 13.000 \\
microcréditos \\
apoyados para \\
fortalecimiento \\
de las pequeñas y \\
medianas empresas \\
(Pymes); según el \\
informe de 2014, \\
fuente de consulta \\
de la investigación, \\
la Alcaldía reporta \\
en este indicador \\
un logro acumulado \\
de 22.981 créditos; \\
sin embargo, la \\
información no se \\
encuentra clasificada \\
por tipos de empresa, \\
lo que dificulta \\
la lectura en los \\
créditos otorgados \\
específicamente para \\
empresas sociales y \\
solidarias.
\end{tabular} & $\begin{array}{l}\text { En los cursos relacionados con las } \\
\text { áreas de emprendimiento, tanto como } \\
\text { área disciplinar en la administración } \\
\text { de empresas, como de aquellos } \\
\text { cursos relacionados con el énfasis, el } \\
\text { aprendizaje está en el hecho de incluir } \\
\text { en los proyectos docentes un análisis } \\
\text { que haga el recorrido por todo el sector } \\
\text { financiero, tratando de identificar } \\
\text { oportunidades adicionales en materia } \\
\text { de fuentes de financiación para este } \\
\text { tipo de proyectos, de tal manera } \\
\text { que se sensibilice hacia de creación, } \\
\text { fortalecimiento y consolidación de este } \\
\text { tipo de empresas, como alternativa } \\
\text { para generación de empleos y aporte } \\
\text { al desarrollo equitativo e incluyente. } \\
\text { Igualmente es tarea de la Funlam } \\
\text { fortalecer cada vez más su visión sobre } \\
\text { estas unidades productivas, teniendo en } \\
\text { cuenta que la investigación como una } \\
\text { de sus funciones sustantivas, da origen a } \\
\text { innovaciones tecnológicas y productivas, } \\
\text { pero también debe concebir dichas } \\
\text { unidades mucho más alla de un proyecto } \\
\text { productivo, como una estrategia para } \\
\text { fortalecer valores como la cooperación, } \\
\text { la autogestión, la asociatividad } \\
\text { y la ayuda mutua, planeando y } \\
\text { operativizando la innovación en la } \\
\text { institución educativa. }\end{array}$ \\
\hline & $\begin{array}{l}\text { Generación de } \\
\text { empleos }\end{array}$ & $\begin{array}{l}\text { Flexibilizar los requisitos } \\
\text { para la generación de } \\
\text { empleos decentes, que } \\
\text { desde los modelos de } \\
\text { aplicación de la política } \\
\text { pública son incoherentes } \\
\text { y muy exigentes, ya } \\
\text { que en este tipo de } \\
\text { economía sus factores } \\
\text { determinantes son la } \\
\text { comunidad y el trabajo, } \\
\text { donde ese trabajo se } \\
\text { produce en cooperación } \\
\text { y comunidad; por tanto, } \\
\text { lo que se generan son } \\
\text { ingresos y no empleo } \\
\text { decente. El concepto } \\
\text { empleo decente es más } \\
\text { propia para las UPA que } \\
\text { se encuentran en etapa } \\
\text { de consolidación. }\end{array}$ & $\begin{array}{c}\text { Generación de } \\
\text { empleos***: } 7 \% \\
\text { de las UPA generan } \\
\text { empleos decentes, el } \\
\text { 93\% restantes solo } \\
\text { generan ingresos } \\
\text { ocasionales; sin } \\
\text { embargo, la totalidad } \\
\text { de las personas que } \\
\text { intervienen en la } \\
\text { investigación afirman } \\
\text { que las actividades } \\
\text { desarrolladas en } \\
\text { las UPA los han } \\
\text { dignificado como } \\
\text { personas. }\end{array}$ & $\begin{array}{l}\text { El aprendizaje para la academia está } \\
\text { en el hecho de ratificar su discurso, } \\
\text { poniendo en centro de creación, } \\
\text { fortalecimiento y consolidación de } \\
\text { unidades empresariales solidarias a la } \\
\text { persona, con este tipo de empresas } \\
\text { sociales y solidarias, las personas } \\
\text { pueden mejorar sus ingresos en el } \\
\text { mediano y largo plazo, pero al mismo } \\
\text { tiempo potencian capacidades y se } \\
\text { autorrealizan. } \\
\text { Teniendo en cuenta que la educación } \\
\text { y la formación son condiciones } \\
\text { fundamentales para el acceso a un } \\
\text { empleo decente y que estas están } \\
\text { catalogadas también dentro de } \\
\text { los derechos fundamentales, otro } \\
\text { aprendizaje está en el sentido de que las } \\
\text { universidades deben ampliar y cualificar } \\
\text { cada vez mas su oferta académica, no } \\
\text { solo desde programas de educación } \\
\text { formal, sino también en educación } \\
\text { continua, que facilite la capacitación en } \\
\text { este tipo de proyectos, para que así mas } \\
\text { personas y comunidades puedan acceder } \\
\text { a un empleo en condiciones dignas y } \\
\text { justas de remuneración. }\end{array}$ \\
\hline
\end{tabular}




\begin{tabular}{|c|c|c|c|c|}
\hline $\begin{array}{l}\text { Categorías de } \\
\text { análsis * }\end{array}$ & Retos & Acciones propuestas & Resultados** & Aprendizajes en el rol de los docentes \\
\hline \multirow[b]{2}{*}{$\begin{array}{c}\text { Fortalecimiento } \\
\text { de UPA }\end{array}$} & $\begin{array}{l}\text { Potenciación } \\
\text { del impacto de } \\
\text { las UPA en la } \\
\text { transformación del } \\
\text { entorno. }\end{array}$ & $\begin{array}{l}\text { Hacer articulación } \\
\text { y extensión del } \\
\text { fortalecimiento de } \\
\text { las UPA, con las } \\
\text { organizaciones sociales } \\
\text { con las que están } \\
\text { vinculadas, para que al } \\
\text { mismo tiempo genere } \\
\text { sensibilización en } \\
\text { acciones preventivas } \\
\text { concretas, integradas al } \\
\text { desarrollo de la actividad } \\
\text { productiva y el cuidado } \\
\text { del medioambiente. }\end{array}$ & $\begin{array}{c}\text { Desde el punto } \\
\text { de vista de la } \\
\text { transformación } \\
\text { del entorno, la } \\
\text { investigación no } \\
\text { encontró cifras. Solo } \\
\text { algunos testimonios } \\
\text { que manifiestan } \\
\text { la participación } \\
\text { de las UPA en } \\
\text { economías de escala, } \\
\text { donde desarrollan } \\
\text { tareas como el } \\
\text { reciclaje, lo cual } \\
\text { genera resultados } \\
\text { importantes para la } \\
\text { reindustrialización, } \\
\text { por el hecho de } \\
\text { que Medellín } \\
\text { es generadora } \\
\text { y consumidora } \\
\text { de materiales de } \\
\text { desechos en grandes } \\
\text { cantidades. }\end{array}$ & $\begin{array}{l}\text { El aprendizaje en este aspecto se } \\
\text { relaciona con la profundización en } \\
\text { el tema de economías de escala, con } \\
\text { una visión de desarrollo basada en } \\
\text { la economía solidaria, considerando } \\
\text { procesos de interacción y construcción } \\
\text { de comunidad que posibilitan el } \\
\text { reconocimiento de cada uno como } \\
\text { persona, el reconocimiento del otro } \\
\text { y el reconocimiento de los espacios } \\
\text { territoriales. En este sentido, las } \\
\text { universidades, mediante actividades } \\
\text { de extensión y proyección, deben } \\
\text { promover el encuentro entre los actores } \\
\text { sociales que forman parte de la UPA } \\
\text { y las organizaciones sociales, desde } \\
\text { el referente de los objetivos comunes } \\
\text { que convocan a ambas partes y en la } \\
\text { perspectiva de que estas realicen alianzas } \\
\text { estrategicas marcadas por la cooperación } \\
\text { para el logro de sus proyectos. }\end{array}$ \\
\hline & $\begin{array}{l}\text { Potenciación de } \\
\text { las personas que } \\
\text { integran las UPA } \\
\text { exitosas. }\end{array}$ & $\begin{array}{l}\text { Identificar y caracterizar } \\
\text { las personas que } \\
\text { integran las UPA } \\
\text { exitosas. Se deben } \\
\text { establecer criterios y } \\
\text { puntos de referencia de } \\
\text { buenas prácticas y cómo } \\
\text { estas se puede extender } \\
\text { o replicar para poder } \\
\text { identificar grupos con } \\
\text { dicho potencial. }\end{array}$ & $\begin{array}{l}\text { La puesta en marcha } \\
\text { y aplicación de la } \\
\text { Política Pública de } \\
\text { Economía Solidaria } \\
\text { está muy reciente, } \\
\text { (Acuerdo } 41 \text { de } \\
2011 \text { del Concejo } \\
\text { de Medellín y } \\
\text { Decreto } 0486 \text { de } \\
2015 \text { por medio del } \\
\text { cual se reglamenta } \\
\text { el Acuerdo } 41 \text { de } \\
2011 \text { ), aún no se } \\
\text { registran cifras de } \\
\text { impacto en cuanto } \\
\text { a mejoramiento } \\
\text { en los índices de } \\
\text { desarrollo humano } \\
\text { en articulación con la } \\
\text { economía solidaria. } \\
\text { En este proceso } \\
\text { de investigación, } \\
\text { los testimonios de } \\
\text { los entrevistados } \\
\text { coinciden en afirmar } \\
\text { que el desarrollo } \\
\text { de actividades de } \\
\text { la UPA, de alguna } \\
\text { manera, los ha } \\
\text { dignificado como } \\
\text { personas. }\end{array}$ & $\begin{array}{l}\text { El aprendizaje principal en este aspecto } \\
\text { está sobre la necesidad de desarrollar } \\
\text { una formación empresarial solidaria, } \\
\text { desde la generación de procesos de } \\
\text { transformación social, potenciando } \\
\text { capacidades críticas y reflexivas a la } \\
\text { luz de una organización solidaria que } \\
\text { sea capaz de asociarse para trabajar } \\
\text { por el beneficio de los asociados o de } \\
\text { la sociedad en general, desarrollando } \\
\text { una actividad productiva o de servicios. } \\
\text { En este sentido, la Funlam puede } \\
\text { implementar proyectos de laboratorio } \\
\text { y de observatorio de este tipo de } \\
\text { emprendimientos, para así reconocer } \\
\text { a sus actores y las características de } \\
\text { sus unidades productivas, en términos } \\
\text { de fortalezas y debilidades para } \\
\text { potencializar las primeras y trabajar en } \\
\text { correctivos de las segundas. }\end{array}$ \\
\hline
\end{tabular}




\begin{tabular}{|c|c|c|c|c|}
\hline $\begin{array}{l}\text { Categorías de } \\
\text { análsis * }\end{array}$ & Retos & Acciones propuestas & Resultados** & Aprendizajes en el rol de los docentes \\
\hline \multirow[b]{2}{*}{$\begin{array}{c}\text { Consolidación } \\
\text { de las UPA }\end{array}$} & $\begin{array}{c}\text { Logro de un } \\
\text { direccionamiento } \\
\text { estratégico preciso } \\
\text { y adecuado, para } \\
\text { las UPA, soportado } \\
\text { en una estructura } \\
\text { organizacional } \\
\text { y operativa } \\
\text { claramente } \\
\text { definida. }\end{array}$ & $\begin{array}{c}\text { Establecer criterios } \\
\text { de consolidación } \\
\text { empresarial solidaria que } \\
\text { pueda evidenciarse en el } \\
\text { propio funcionamiento } \\
\text { de organizaciones } \\
\text { sociales y solidarias, } \\
\text { basadas en prácticas } \\
\text { democráticas, } \\
\text { humanistas } \\
\text { autogestionarias y sin } \\
\text { ánimo de lucro. }\end{array}$ & $\begin{array}{l}\text { Todas las UPA de los } \\
\text { entrevistados poseen } \\
\text { sus estructuras } \\
\text { administrativas } \\
\text { claramente definidas } \\
\text { en sus planes de } \\
\text { negocio: Asamblea } \\
\text { General, Junta } \\
\text { Directiva, diferentes } \\
\text { comités, Gerencia, } \\
\text { Junta de Vigilancia } \\
\text { y Revisoría Fiscal; } \\
\text { sin embargo, en la } \\
\text { práctica aún en las } \\
\text { UPA consolidadas } \\
\text { estas estructuras son } \\
\text { difusas, muchos roles } \\
\text { son compartidos por } \\
\text { varios integrantes. }\end{array}$ & $\begin{array}{l}\text { Una organización social y solidaria debe } \\
\text { desarrollar sus actividades en coherencia } \\
\text { con procesos de transformación social } \\
\text { que potencien capacidades críticas } \\
\text { y reflexivas a la luz de principios } \\
\text { solidarios. Las responsabilidades } \\
\text { asumidas por las personas en los } \\
\text { procesos organizacionales de las UPA } \\
\text { deben sustentarse en la autogestión y } \\
\text { participación, no simplemente como } \\
\text { aceptación de los principios solidarios y } \\
\text { empresariales, sino como un asunto de } \\
\text { mayor incorporación en esas prácticas, } \\
\text { para asegurar ingresos, pero también } \\
\text { participación en la toma de decisiones }\end{array}$ \\
\hline & $\begin{array}{l}\text { Fomento del } \\
\text { relacionamiento } \\
\text { entre las UPA. }\end{array}$ & $\begin{array}{l}\text { Acompañar por parte del } \\
\text { Estado la generación de } \\
\text { vínculos de cooperación } \\
\text { productiva para el } \\
\text { trabajo coordinado, que } \\
\text { les permita potenciar } \\
\text { la capacidad operativa } \\
\text { y generar un impacto } \\
\text { social de mayores } \\
\text { proporciones, más allá } \\
\text { de la identificación } \\
\text { mutua o la agrupación } \\
\text { en categorías. }\end{array}$ & $\begin{array}{c}\text { La investigación } \\
\text { encontró } 20 \\
\text { intervenciones en } \\
\text { Redes de economía } \\
\text { solidaria en el } \\
\text { periodo comprendido } \\
\text { entre } 2012 \text { y 2015; } \\
\text { sin embargo, los } \\
\text { informes consultados } \\
\text { no precisan } \\
\text { cuántas de esas } \\
\text { intervenciones se } \\
\text { hicieron en redes } \\
\text { consolidadas. } \\
\text { Por otro lado, } \\
\text { los testimonios } \\
\text { de beneficiarios } \\
\text { tampoco evidencian } \\
\text { asociaciones } \\
\text { productivas. Al } \\
\text { igual que en otros } \\
\text { indicadores, es muy } \\
\text { prematuro hablar de } \\
\text { la consolidación de } \\
\text { redes, por el corto } \\
\text { tiempo de aplicación } \\
\text { de la Política Pública } \\
\text { de Economía } \\
\text { Solidaria. }\end{array}$ & $\begin{array}{l}\text { La sensiblización en el tema de creación, } \\
\text { fortalecimiento y consolidación de } \\
\text { empresas sociales y solidarias implica } \\
\text { la sensibilización de trabajo en red, } \\
\text { para darle soporte a la realización de } \\
\text { proyectos conjuntos que nutran el } \\
\text { modelo cooperativo y solidario. Redes } \\
\text { de Economía Solidaria basado en valores } \\
\text { de confianza sobre pensamientos } \\
\text { comunes y acciones compartidas } \\
\text { para promocionar el trabajo entre } \\
\text { las organizaciones y con su base } \\
\text { social, con lo cual también quedan } \\
\text { aprendizajes sobre las necesidades } \\
\text { de ahondar en temas de: consumo } \\
\text { responsable, comercio justo, producción } \\
\text { agroecológica, comercialización } \\
\text { comunitaria, prácticas de intercambio } \\
\text { solidario no condicionadas por dinero, } \\
\text { educación y cultura solidaria, así como } \\
\text { en los temas relacionados con políticas } \\
\text { públicas y desarrollo local. }\end{array}$ \\
\hline
\end{tabular}

* Las categorías de análisis fueron tomadas de acuerdo con la aplicación de la Política Pública de Economía Social Solidaria, según los indicadores que para esta economía, contienen los dos últimos planes de desarrollo de la ciudad de Medellín.

** Los resultados fueron tomados de: Alcaldía de Medellín: Departamento Administrativo de Planeación, Subdirección de Planeación Económica y Social del Municipio de Medellín (2014). Informe de Economía Solidaria.

*** Los datos de empleo fueron tomados de: Personería de Medellín (2014). Las Unidades Productivas Asociativas alternativa de empleo digno utopía o realidad (Versión 2-2014). Informe final de Investigación de la línea Económica de Planeación Local y Presupuesto participativo. Observatorio de Planeación Local y Presupuesto participativo. Presentado por la profesional Guiomar Bibiana Peralta Robledo. 